\title{
Genetic and Epigenetic Studies in Diabetic Kidney Disease
}

\author{
Harvest F. Gu* \\ Center for Pathophysiology, School of Basic Medicine and Clinical Pharmacy, China Pharmaceutical University, Nanjing, \\ China
}

Chronic kidney disease is a worldwide health crisis, while diabetic kidney disease (DKD) has become the leading cause of end-stage renal disease (ESRD). DKD is a microvascular complication and occurs in $30-40 \%$ of diabetes patients. Epidemiological investigations and clinical observations on the familial clustering and heritability in DKD have highlighted an underlying genetic susceptibility. Furthermore, DKD is a progressive and long-term diabetic complication, in which epigenetic effects and environmental factors interact with an individual's genetic background. In recent years, researchers have undertaken genetic and epigenetic studies of DKD in order to better understand its molecular mechanisms. In this review, clinical material, research approaches and experimental designs that have been used for genetic and epigenetic studies of DKD are

OPEN ACCESS

Edited by:

Calli Dendrou,

Wellcome Centre for Human Genetics

(WT), United Kingdom

Reviewed by:

Alexander Peter Maxwell,

Queen's University Belfast,

United Kingdom

Taku Miyagawa

Tokyo Metropolitan Institute

of Medical Science, Japan

*Correspondence:

Harvest F. Gu

feng.gu@cpu.edu.cn

Specialty section:

This article was submitted to

Genetic Disorders,

a section of the journal

Frontiers in Genetics

Received: 03 December 2018

Accepted: 08 May 2019

Published: 07 June 2019

Citation:

Gu HF (2019) Genetic and Epigenetic Studies in Diabetic Kidney Disease.

Front. Genet. 10:507. doi: 10.3389/fgene.2019.00507 described. Current information from genetic and epigenetic studies of DKD and ESRD in patients with diabetes, including the approaches of genome-wide association study (GWAS) or epigenome-wide association study (EWAS) and candidate gene association analyses, are summarized. Further investigation of molecular defects in DKD with new approaches such as next generation sequencing analysis and phenome-wide association study (PheWAS) is also discussed.

Keywords: diabetic kidney disease, diabetes, end-stage renal disease, genetics, epigenetics, phenotypes

\section{INTRODUCTION}

Diabetes is a major public health problem that is approaching epidemic proportions globally. According to the latest report from the IDF, the prevalence of diabetes will increase from 425 million persons in 2017 to 629 million by 2045 (IDF 2017 ). Diabetic kidney disease (DKD, previously termed diabetic nephropathy, DN) is a microvascular complication and progresses gradually over many years in approximately $30-40 \%$ of individuals with T1D and T2D mellitus (Harjutsalo and Groop, 2014; Thomas et al., 2015; Barrett et al., 2017). DKD is now the main cause of chronic kidney disease (CKD) worldwide and the leading cause of end-stage-renal disease (ESRD) requiring renal replacement therapy (dialysis or transplantation). The presence of CKD is the single strongest predictor of mortality for persons with diabetes (Dousdampanis et al., 2016; Papadopoulou-Marketou et al., 2017). Pathological findings in DKD include glomerular

Abbreviations: ACR, albumin-to-creatinine ratio; ADA, American Diabetes Association; BMI, body mass index; CNV, copy number variant; DKD, diabetic kidney disease; ESRD, end-stage renal disease; EWAS, epigenome-wide association study; GFR, glomerular filtration rate; GWAS, genome-wide association study; IDF, International Diabetes Federation; IHME, Institute for Health Metrics and Evaluation; LD, Linkage disequilibrium; PheWAS, phenome-wide association study; SNP, single nucleotide polymorphism; T1D, type 1 diabetes; T2D, type 2 diabetes; UAE, urinary albumin excretion.

${ }^{1}$ http://www.diabetesatlas.org/ 
hypertrophy, mesangial matrix expansion, reduced podocyte number, glomerulosclerosis, tubular atrophy and tubulointerstitial fibrosis. Clinical criteria used to diagnose the subjects with DKD are urine ACR higher than $300 \mathrm{mg} / \mathrm{g}$, while microalbuminuria is diagnosed when ACR is between 30-300 mg/g (Bouhairie and McGill, 2016). Accumulating evidence has indicated that podocyte loss and epithelial dysfunction play important roles in DKD pathogenesis with further progression associated with inflammation but the exact molecular mechanisms responsible for DKD are not fully known (Badal and Danesh, 2014; Reidy et al., 2014; Gnudi et al., 2016).

Both clinical and epidemiological studies have demonstrated that there is familial aggregation of DKD in different ethnic groups, indicating that genetic factors contribute to development of the disease. Furthermore, genetic risk factors in DKD interact with the environmental factors (for example, lifestyle, diet and medication) (Freedman et al., 2007a; Murea et al., 2012; Thomas et al., 2012; Kato and Natarajan, 2014). Figure 1 is a schematic diagram representing the relationship between genetic, epigenetic and environmental factors that are involved in the development and progression of DKD. Genetic studies of DKD are mainly focused on association analyses between genomic DNA variation (for example, single nucleotide polymorphisms, SNPs, copy number variants, CNVs, and microsatellites) and clinical phenotypes of the disease (Freedman et al., 2007a; Gu and Brismar, 2012; Thomas et al., 2012; Florez, 2016). Epigenetics studies of DKD examine potentially heritable changes in gene expression that occur without variation in the original DNA nucleotide sequence (Villeneuve and Natarajan, 2010; Kato and Natarajan, 2014; Thomas, 2016; Keating et al., 2018). Therefore, epigenetic studies of DKD may provide information to help understand how environmental factors modify the expression of genes that are involved in DKD progression. Combined genetic, epigenetic and phenotypic studies together may generate information to understand new pathogenic pathways and to search for new biomarkers for early diagnosis and prediction as part of prevention programs in DKD. The results may also be useful in finding novel targets for the treatment of DKD.

SNPs are the most common form of genomic DNA variation. The updated dbSNP database of more than 500 million reference SNPs (rs) with allele frequency data ${ }^{2}$ has provided fundamental information for genetic studies of complex diseases including, DKD. The genetic studies in DKD have implicated previously unsuspected biological pathways and subsequently improved our knowledge for understanding of the genetic basis of the disease. For most common traits studied in DKD, however, the identified genes and their SNPs only explain a fraction of associated risk, suggesting that human genomic DNA variations are only a part of underlying susceptibility to DKD. This has led to evolving interest in epigenetics to help explain some of the missing heritability of DKD. Epigenetic mechanisms mainly consist of DNA methylation, chromosome histone modification and noncoding RNA (ncRNA) regulation (Kato and Natarajan, 2014; Allis and Jenuwein, 2016). Epigenetic related ncRNAs include miRNA, siRNA, piRNA, and lncRNA (Holoch and Moazed, 2015).

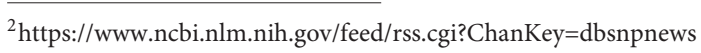

There are more than 30,000 identified CpG islands in the human genome. Detailed information for these $\mathrm{CpG}$ islands can be found in the public database ${ }^{3}$. The $\mathrm{CpG}$ islands are defined as stretches of DNA > 200 bp long with a GC percentage greater than $50 \%$ and an observed-to-expected $\mathrm{CpG}$ ratio of more than $60 \%$. The $\mathrm{CpG}$ islands are often found at promoters and contain the $5^{\prime}$ end of the transcript, while DNA methylation occurs at $5^{\prime}$-cytosines of "CpG" dinucleotides (Cross and Bird, 1995). In $\mathrm{DKD}$, the effects of DNA methylation have been studied in terms of transgenerational inheritance of the disease to explore environmental and other non-genetic factors that may influence epigenetic modifications in the genes involved in DKD (Deaton and Bird, 2011; Jones, 2012). Identification of differentially methylated $\mathrm{CpG}$ sites in promoters or other functional regions of genes and the analysis of the DNA methylation changes that are associated with DKD have become the most common approaches used in epigenetic studies of the disease (Villeneuve and Natarajan, 2010; Kato and Natarajan, 2014; Thomas, 2016). Furthermore, ncRNAs, particularly long ncRNAs are known to be involved in epigenetic processes. ncRNAs certainly play an important role in chromatin formation, histone modification, DNA methylation and consequently gene transcription silencing.

Genetic and epigenetic studies of DKD, initially using candidate gene approaches and more recently at genome-wide scale (known as GWAS and EWAS), have been undertaken to identify many genes conferring susceptibility or resistance to DKD. In this review, clinical phenotypes, research approaches and experimental designs that have been used for genetic and epigenetic studies of DKD are described. These research approaches and experimental designs can also be used for study of CKD. Current information from genetic and epigenetic studies of DKD is summarized. Further investigation of molecular defects in DKD with new generation sequencing analyses and phenome-wide association studies (PheWAS) are discussed.

\section{BIOLOGICAL MATERIAL, RESEARCH APPROACHES AND STUDY DESIGNS USED IN GENETIC AND EPIGENETIC INVESTIGATIONS OF DIABETIC KIDNEY DISEASE}

Two major research approaches either at genome-wide scale or focused on candidate gene(s) have been widely used for comparative studies between cases (patients with DKD) and controls (diabetes patients without DKD). Casecontrol studies by recruiting large numbers of subjects can increase the statistical power of reported associations. The aim is to discover the genes presented differentially in genomic structure or genetic expression. Genome-wide or epigenome-wide association studies (GWAS or EWAS) are hypothesis-generating approaches (Rakyan et al., 2011; Do et al., 2017; Lappalainen and Greally, 2017). These

\footnotetext{
${ }^{3}$ https://genome.ucsc.edu/cgi-bin/hgTables

${ }^{4}$ https://en.wikipedia.org/wiki/CpG_site
} 


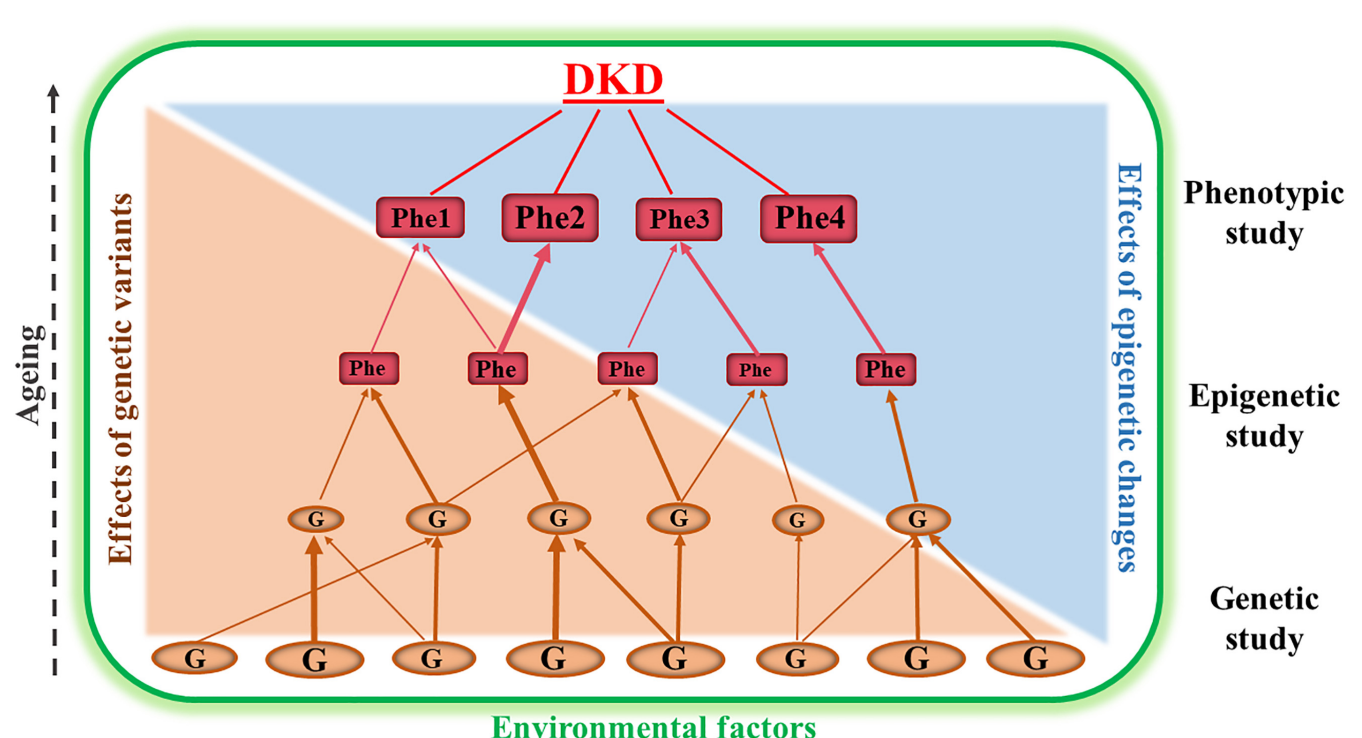

FIGURE 1 | This is a schematic diagram representing the relationship between genetic, epigenetic and phenotypic studies in diabetic kidney disease (DKD). Genetic association studies are fundamentally important for identification of susceptibility or resistance genes (G). Epigenetic studies analyzing genomic DNA methylation changes, chromosome histone modification and ncRNA regulation are useful for dissecting the interaction of the genes with environmental factors. The combined data from genetic, epigenetic and phenotypic (Phe) studies may provide the opportunity for us to understand new pathways underlying the pathogenesis of DKD and to discover new biomarkers for early diagnosis and to find targets for prevention and treatment programs of this disease. The different sizes of the "G" and "Phe" represent the variation of genetic and phenotypic effects.

study designs have benefited from rapid development of human genome research, including the creation of publicly available databases of SNPs, haplotypes and CpG islands and the rapid technical improvements in analyzing genomic variation using high-throughput techniques and highdensity SNP or CpG arrays. Another approach is to focus on candidate genes and study a more limited number of genes potentially involved in the pathogenesis of DKD based upon our known knowledge or hypothesis. In genetic and epigenetic studies of DKD, DNA samples used are commonly extracted from peripheral blood samples because they are clinically accessible. Dick et al. (2014) have comparatively analyzed DNA methylation changes related to BMI by using both approaches of whole-blood DNA methylation profiling and adipose tissue specific methylation measurement. Data suggests that analysis of blood DNA methylation is worthwhile because the results can reflect the DNA methylation changes in relevant tissues for a particular phenotype. Nevertheless, there is still limited information concerning the correlation between whole blood DNA methylation profiles and kidney tissue specific DNA methylation changes in part due to the heterogeneity of cell types within the kidney. To improve the tissue specific DNA methylation analysis of kidney diseases, including DKD, it is necessary to construct biobanks of renal biopsies. Karolinska Institutet has established a biobank in KaroKidney with more than 750 renal biopsies ${ }^{5}$. The advantages and limitations of these two approaches, as well as the clinical materials and experimental

${ }^{5} \mathrm{http} / / /$ karokidney.org design used in genetic and epigenetic studies of DKD are summarized in Table $\mathbf{1 .}$

\section{RECENT DATA FROM GENETIC STUDIES IN DIABETIC KIDNEY DISEASE}

Considerable amounts of data from genetic studies in DKD have accumulated. A list of the genes that are reported to be associated with susceptibility or resistance to DKD are summarized in Table 2. The genes are listed in alphabetical order. Surprisingly, there are more than 150 genes. Most of them have been identified by genetic association studies employing candidate gene approaches over the past 20 years. Furthermore, a number of GWAS in DKD have been published in the last 10 years. By using GWAS approaches, approximately 33 genes have been found to be associated with the DKD, i.e., ABCG2, AFF3, AGER, APOL1, AUH, CARS, CERS2, CDCA7/SP3, CHN2, CNDP1, ELMO1, ERBB4, FRMD3, GCKR, GLRA3, KNG1, LIMK2, MMP9, NMUR2, MSRB3/HMGA2, MYH9, PVT1, RAET1L, RGMA/MCTP2, RPS12, SASH1, SCAF8/CNKSR3, SHROOM3, SLC12A3, SORBS1, TMPO, UMOD, and ZMIZ1 (Hanson et al., 2007; Sandholm et al., 2012, 2014; Maeda et al., 2013; Thameem et al., 2013; Bailey et al., 2014; Palmer et al., 2014; Guan et al., 2016; Teumer et al., 2016; Lim et al., 2017; Roden, 2017; Charmet et al., 2018; van Zuydam et al., 2018). However, most of these genes $(\sim 80 \%)$ reportedly associated with DKD still need to be confirmed by further replication studies and detailed analysis of their functional role in DKD in experimental models. Polymorphisms in these candidate 
TABLE 1 | Clinical material, research approaches and experimental designs used in genetic and epigenetic studies of diabetic kidney disease.

\begin{tabular}{|c|c|c|c|}
\hline & Study & Advantage & Disadvantage \\
\hline \multirow[t]{3}{*}{ Clinical material } & Blood or saliva & Clinical accessible & Possible bias from mixed cell types \\
\hline & Kidney tissues & $\begin{array}{l}\text { Gene specific methylation and } \\
\text { expression can be analyzed }\end{array}$ & Difficult to access \\
\hline & Renal cell lines & Intervention and mechanism study & In vitro experiment \\
\hline \multirow[t]{3}{*}{ Research approach } & $\begin{array}{l}\text { Candidate gene DNA variation or } \\
\text { methylation analysis }\end{array}$ & $\begin{array}{l}\text { Study of candidate genes with potential } \\
\text { biological functions }\end{array}$ & Less information on the studied genes \\
\hline & $\begin{array}{l}\text { Global genomic DNA variation or } \\
\text { methylation analyses }\end{array}$ & $\begin{array}{l}\text { General information of DNA } \\
\text { polymorphisms and methylation in } \\
\text { genome wide scale }\end{array}$ & $\begin{array}{l}\text { Analysis of repeated sequence } \\
\text { alteration and methylation changes } \\
\text { Lack of gene specific information }\end{array}$ \\
\hline & $\begin{array}{l}\text { Genome or epigenome-wide } \\
\text { association studies }\end{array}$ & $\begin{array}{l}\text { Numerous SNP, CNV or CpG sites } \\
\text { methylation information in genome wide } \\
\text { scale }\end{array}$ & Higher cost Strict validation is needed \\
\hline \multirow[t]{4}{*}{ Experimental design } & Case-control study & Many cohorts exist & $\begin{array}{l}\text { Difficult to control genetic and } \\
\text { environmental confounders }\end{array}$ \\
\hline & Twin study & Control for genetics & Few large cohorts \\
\hline & Family study & Study of potential inheritance & Few large cohorts \\
\hline & Longitudinal study & Determine causality & Time consuming \\
\hline
\end{tabular}

CNV, copy-number variation; CpG sites, the regions of DNA where a cytosine nucleotide is followed by a guanine nucleotide in the linear sequence of bases along its $5^{\prime}$ $\rightarrow$ 3' direction; SNP, single-nucleotide polymorphism.

genes association with DKD studies are listed in Table $\mathbf{2 A}$, while their potential biological relevance and genetic effects in DKD are briefly described. Of them, 34 genes are originally predicted by GWAS and the statistical association with DKD summarized in Table 2B.

The CNDP1 (carnosine dipeptidase 1) gene is located in chromosome 18q22.3 and contains 5-leucine (CTG) trinucleotide repeat length polymorphism (D18S880) in the coding region (Wanic et al., 2008). This trinucleotide repeat polymorphism is found to have gender specificity and to confer the susceptibility for DKD and ESRD in T2D (Albrecht et al., 2017b). Furthermore, serum carnosinase $(\mathrm{CN}-1)$ activity is negatively correlated with time on hemodialysis (Peters et al., 2016). In addition, several SNPs in this gene are also associated with DKD and ESRD (Janssen et al., 2005; Freedman et al., 2007b; McDonough et al., 2009; Alkhalaf et al., 2010; Mooyaart et al., 2010; Ahluwalia et al., 2011b; Chakkera et al., 2011; Kurashige et al., 2013). Interestingly, an experimental study in BTBR ob/ob mice has demonstrated that treatment with carnosine as the target of CNDP1 improves glucose metabolism and albuminuria, suggesting that carnosine may be a novel therapeutic strategy to treat patients with DKD (Albrecht et al., 2017a).

The ELMO1 (engulfment and cell motility 1) gene is located on chromosome p14.1 and encodes a member of the engulfment and cell motility protein family. The protein interacts with dedicator of cytokinesis proteins and subsequently promotes phagocytosis and cell migration. Increased expression of ELMO1 and dedicator of cytokinesis 1 may promote glioma cell invasion (Patel et al., 2010). Furthermore, several SNPs in this gene are found to be associated with DKD in both T1D and T2D (Shimazaki et al., 2005, 2006; Craig et al., 2009; Leak et al., 2009; Pezzolesi et al., 2009a; Hanson et al., 2010; Wu et al., 2013; Alberto Ramirez-Garcia et al., 2015; Bodhini et al., 2016; Hathaway et al., 2016; Mehrabzadeh et al., 2016; Sharma et al., 2016). The variants associated with DKD, however, are different in the several populations studied, suggesting the presence of allelic heterogeneity probably resulting from the diverse ancestral genetic backgrounds of the different racial groups.

The FRMD3 (FERM domain containing 3) gene is located in chromosome 9q21.32. The FRMD3 gene is expressed in adult brain, fetal skeletal muscle, thymus, ovaries, and podocytes (Ni et al., 2003). Pezzolesi et al. (2009b) have demonstrated that FRMD3 expression in kidneys of a DKD mouse model is decreased as compared with non-diabetic mice. Genetic polymorphisms in the FRMD3 gene are associated with DKD and ESRD in T1D and T2D (Freedman et al., 2011; Al-Waheeb et al., 2016). Furthermore, the members of the bone morphogenetic protein (BMP) interact with FRMD3, which implies that FRMD3 may influence the risk of DKD through regulation of the BMP pathway (Martini et al., 2013; Palmer and Freedman, 2013).

The MMP9 (matrix metallopeptidase 9) gene is located in chromosome 20q13.12. The MMP family members are involved in the breakdown of extracellular matrix (ECM) in physiological processes, such as tissue remodeling, reproduction and embryonic development, while $M M P 9$ is the ninth member in the family. MMP9 may play an essential role in local proteolysis of the extracellular matrix and in leukocyte migration. Moreover, MMPs, including $M M P$ 9, are zinc-dependent endopeptidases and the major proteases in ECM degradation. There are common variants such as rs3918242 (-1562C/T) and microsatellites (CA)n in the promoter region and several SNPs rs481480, rs2032487, rs4281481, rs3752462 and rs3918242 are found to be associated with the susceptibility to DKD (Hirakawa et al., 2003; Nair et al., 2008; Ahluwalia et al., 2009; Freedman et al., 2011; Cooke et al., 2012; Zhang et al., 2015; Feng et al., 2016).

Both UMOD (uromodulin) and SLC12A3 (solute carrier family 12 member 3 ) genes are located in the same chromosome but in short and long arms, respectively, i.e., 16p12.3 and 16q13. SLC12A3 is also known as thiazide-sensitive sodiumchloride cotransporter in kidney distal convoluted tubules, 
TABLE 2A | Current data from genetic association studies in diabetic kidney disease by using candidate gene approach.

\begin{tabular}{|c|c|c|}
\hline Gene symbol & Genomic DNA polymorphisms & Disease \\
\hline ABCG2 & rs2231142 & T2D-uric acid \\
\hline$A C A C B$ & rs2268388 & T2D-DKD \\
\hline$A C E$ & $\begin{array}{l}\text { rs4646994 (289bp Alu I/D), rs4343, rs1799752, rs1800764, } \\
\text { rs12449782 }\end{array}$ & T1D-DKD, T2D-DKD, T2D-ESRD \\
\hline$A D P O Q$ & $\begin{array}{l}\text { rs266729, rs17300539, rs2241766, rs1063537, rs2241767, } \\
\text { rs2082940 }\end{array}$ & T1D-DKD, T2D-DKD \\
\hline ADRB2 & Arg16Gly, Gln27Glu & T2D-eGFR \\
\hline AFF3 & rs7583877 & T1D-ESRD \\
\hline AGER & rs2070600, rs2071288 & T2D-DKD \\
\hline$A G T$ & rs5050, rs4762, Met235Thr & T2D-DKD \\
\hline AGTR1 & rs5186, +1166A/C, $-106 \mathrm{C} / \mathrm{T}, \mathrm{rs} 12695897$ & T1D-DKD, T2D-ESRD \\
\hline AGTR2 & $+1675 \mathrm{G} / \mathrm{A},+1818 \mathrm{~A} / \mathrm{T}$ & T1D-DKD \\
\hline AKR1B1 & rs759853 & T2D-DKD, T2D-ESRD \\
\hline ALOX12 & rs14309 & T2D-DKD+CVD \\
\hline$A P O E$ & e4 allele, e2/e3 alleles & T2D-DKD \\
\hline APOL1 & rs136161, rs713753, rs767855, Ser342Gly, lle384Met & T2D-ESRD \\
\hline$A \cup H$ & rs773506 & T2D-ESRD \\
\hline$B I D$ & rs181390 & T1D-ESRD \\
\hline CALD1 & rs3807337 & T1D-DKD \\
\hline CARS & rs452041, rs739401 & T1D-DKD, T2D-DKD \\
\hline CASR & rs3804594 & T2D-DKD \\
\hline CAT & rs1001179 & T2D-ESRD \\
\hline CERS2 & rs267734, rs267738 & T1D-DKD, T2D-DKD \\
\hline $\mathrm{CDH} 13$ & rs11646213, rs3865188 & T1D-ESRD \\
\hline $\mathrm{CFH}$ & rs379489 & T2D-ESRD \\
\hline CHN2 & rs39059 & T1D-DKD \\
\hline CNDP1 & $\begin{array}{l}\text { (CTG)5, rs4892249, rs6566815, rs2346061, rs1295330, } \\
\text { rs6566810, rs } 11151964, \text { rs } 17817077\end{array}$ & $\begin{array}{l}\text { T2D-dialysis, T2D-DKD, T1D-ESRD, } \\
\text { T2D-ESRD }\end{array}$ \\
\hline CNDP2 & rs7577, rs4892247 & T2D-ESRD \\
\hline CYP11B2 & $-344 \mathrm{~T} / \mathrm{C}$ & T2D-DKD \\
\hline COQ5 & rs1167726, rs614226, rs1167725 & T1D-ESRD \\
\hline COX6A1 & rs12310837 & T1D-ESRD \\
\hline $\operatorname{cox} 10$ & rs7213412 & T1D-ESRD \\
\hline CUBN & rs1801239 & T1D-albuminuria, T2D-ESRD \\
\hline CYBA & rs4673, rs9932581 & T1D-ESRD, T2D-DKD \\
\hline eNOS & $-786 \mathrm{C} / \mathrm{T},+786 \mathrm{~T} / \mathrm{C},+894 \mathrm{G} / \mathrm{T}$, Glu298Asp & T1D-DKD, T2D-DKD \\
\hline ELMO1 & $\begin{array}{l}\text { rs741301, rs1345365, rs11769038, rs10951509, rs1882080, } \\
\text { rs6462776, rs6462777 }\end{array}$ & T1D-DKD, T1D-ESRD, T2D-DKD \\
\hline ENPP1 & rs1044498, rs7754586, rs1974201 & T1D-DKD, T2D-DKD, T2D-ESRD \\
\hline EPHX2 & rs751141 & T2D-DKD \\
\hline$E P O$ & rs1617640 & T1D-ESRD, T2D-DKD \\
\hline ERBB4 & rs7588550 & T1D-DKD \\
\hline ESR1 & rs12197043, rs11964281, rs1569788, rs9340969 & T2D-DKD \\
\hline FNDC5 & rs16835198 & T2D-DKD \\
\hline FRMD3 & $\begin{array}{l}\text { rs1888747, rs10868025, rs942280, rs942278, rs942263, } \\
\text { rs1535753, rs2378658, rs13288659 }\end{array}$ & T1D-ESRD, T2D-DKD \\
\hline GAS6 & Intron 8, c.834+7G/A & T2D-DKD \\
\hline GATC & rs2235222, rs7137953 & T1D-ESRD \\
\hline GCK & rs730947 & T2D-ESRD \\
\hline GCKR & rs1260326 & T2D-eGFR \\
\hline GFPT2 & lle147Val & T2D-DKD \\
\hline GLRA3 & rs1564939 & T1D-AER \\
\hline GPX1 & rs3448 & T1D-DKD \\
\hline
\end{tabular}


TABLE 2A | Continued

\begin{tabular}{|c|c|c|}
\hline Gene symbol & Genomic DNA polymorphisms & Disease \\
\hline GREM1 & rs1129456 & T1D-DKD \\
\hline GSTP1 & rs1695 (lle105Val) & T2D-DKD, T2D-ESRD \\
\hline H19-/GF2 cluster & rs2839698, rs10732516, rs201858505 & T2D-DKD \\
\hline$H I F 1 \alpha$ & rs11549465 (Pro582Ser) & T1D-DKD, T2D-DKD \\
\hline HO1 & $-413 \mathrm{~T} / \mathrm{A}$ & T2D-DKD \\
\hline HSP70 & rs2763979, rs2227956 & T2D-DKD \\
\hline ICAM1 & rs5498 & T1D-DKD, T2D-DKD \\
\hline IGFBP1 & rs1065780, rs3828998, rs3793344, rs4619 & T2D-DKD \\
\hline IGF2BP2 & rs4402960 & T2D-DKD \\
\hline IL1a & $-889 \mathrm{C} / \mathrm{T}$ & T2D-DKD \\
\hline IL1 $\beta$ & $\mathrm{rs} 16944,-511 \mathrm{C} / \mathrm{T}$ & T2D-DKD \\
\hline IL6 & $-634 \mathrm{G} / \mathrm{C},-174 \mathrm{G} / \mathrm{C}, \mathrm{rs} 1800796, \mathrm{rs} 1524107, \mathrm{rs} 1800795, \mathrm{rs} 1800796$ & T2D-DKD \\
\hline IL10 & $-819 T / C,-592 A / C,-1082 A / G$ & T2D-DKD \\
\hline IL18 & rs360719 & T2D-DKD \\
\hline INSR & rs2059806 & T2D-DKD \\
\hline IRAK4 & rs4251532 & T2D-DKD \\
\hline KCNQ1 & I/D in intron 12, rs2237897 & T2D-eGFR, T2D-DKD \\
\hline KLRA1 & rs2168749 & T1D-ESRD \\
\hline KNG1 & $+7965 \mathrm{C} / \mathrm{T}$ & T1D-DKD \\
\hline LIMK2 & rs2106294 & T2D-ESRD \\
\hline LTA & Thr60Asn & T1D-DKD \\
\hline LRP2 & rs17848169 & T2D-ESRD \\
\hline MAPRE1P2 & rs1670754 & T1D-ESRD \\
\hline MCF2L2 & Leu359lle & T1D-DKD \\
\hline MGP & $-138 \mathrm{~T} / \mathrm{C}$ & T2D-DKD \\
\hline MME & rs3796268, rs3773885 & T1D-DKD \\
\hline MMP12 & rs1277718, rs652438, Asn357Ser & T1D-DKD \\
\hline MMP9 & (CA)n in promoter, rs481480, rs2032487, rs4281481, rs3752462, rs3918242 & T2D-ESRD, T2D-DKD \\
\hline NMUR2 & rs982715, rs4958531, rs4958532, rs4958535 & T1D-DKD \\
\hline MSC & rs9298190 & T1D-ESRD \\
\hline MT2A & rs28366003 & T2D-DKD \\
\hline MTHFR & rs1801133 & T1D-DKD, T2D-DKD \\
\hline MTOR & rs7212142 & T2D-DKD \\
\hline MyD88 & rs6853 & T2D-DKD \\
\hline MYH9 & rs5750250 & T2D-ESRD \\
\hline NCALD & $\mathrm{rs} 1131863,+999 \mathrm{~T} / \mathrm{A},+1298 \mathrm{~A} / \mathrm{C},+1307 \mathrm{~A} / \mathrm{G}$ & T2D-DKD \\
\hline near IRS2 & rs1411766 & T1D-DKD, T1D-ESRD, T2D-DKD \\
\hline NOS2 & rs1137933 & T2D-DKD \\
\hline NOS3 & rs3918188, Glu298Asp, Gly894Thr & T1D-DKD, T2D-DKD \\
\hline NQO1 & rs1800566 & T2D-DKD \\
\hline NPHS1 & rs35238405 & T2D-ESRD \\
\hline NPY & Leu7Pro & T1D-DKD \\
\hline PACRG & rs2147653, rs1408705 & T1D-ESRD \\
\hline PAl1 & $4 \mathrm{G} / 5 \mathrm{G}$ & T2D-DKD \\
\hline PARK2 & rs4897081 & T2D-DKD \\
\hline PARP1 & C410T, G1672A, Val762Ala & T2D-DKD \\
\hline PFKFB2 & rs17258746, rs11120137 & T2D-DKD \\
\hline PLEKHH2 & rs1368086, rs725238, rs11886047 & T1D-DKD \\
\hline PLXDC2 & rs1571942, rs12219125 & T1D-DKD \\
\hline PON1 & Leu55Met, Gln192Arg & T1D-DKD, T2D-ACR \\
\hline PON2 & rs12704795 & T2D-DKD \\
\hline PPARG & rs1805192, rs1801282 & T1D-DKD, T2D-DKD \\
\hline
\end{tabular}


TABLE 2A | Continued

\begin{tabular}{|c|c|c|}
\hline Gene symbol & Genomic DNA polymorphisms & Disease \\
\hline PPARGC1A & Gly482Ser & T2D-DKD \\
\hline PROX1 & rs340841 & T2D-DKD \\
\hline PSMD9 & rs1043307, rs14259, +460A/G, +437T/C, Glu197Gly & T2D-DKD \\
\hline PRKCB1 & $-1504 \mathrm{C} / \mathrm{T},-546 \mathrm{C} / \mathrm{T},-348 \mathrm{~A} / \mathrm{G},-278 \mathrm{C} / \mathrm{T},-238 \mathrm{C} / \mathrm{G}$ & T1D-DKD, T2D-eGFR \\
\hline PVT1 & rs2648875, rs2720709 & T2D-ESRD \\
\hline RAGE & $-429 \mathrm{~T} / \mathrm{C},-374 \mathrm{~T} / \mathrm{A},+2184 \mathrm{~A} / \mathrm{G}$ & T1D-ESRD, T2D-DKD \\
\hline RAET1L & rs1543547 & T1D-DKD \\
\hline RBP4 & rs3758538, rs10882278, rs7094671, rs12766992 & T2D-eGFR \\
\hline REN & rs41317140 & T2D-DKD \\
\hline RREB1 & rs9379084, rs41302867 & T2D-ESRD \\
\hline RTN1 & rs1952034, rs12431381, rs12434215 & T2D-ESRD \\
\hline SASH1 & rs6930576 & T2D-ESRD \\
\hline SCAF8/CNKSR3 & rs12523833 & T2D-DKD \\
\hline SEMA6D/SLC24A5 & rs12917114 & T1D-ESRD \\
\hline SERPINB7 & rs1720843 & T2D-DKD \\
\hline SERPINE1 & 4G/5G polymorphism & T2D-DKD \\
\hline SHROOM3 & rs1739721 & T2D-eGFR \\
\hline SIK1 & rs2838302 & T1D-ESRD \\
\hline SIRT1 & rs4746720 & T2D-DKD \\
\hline SLC2A1 & rs3820589, Haell polymorphism & T1D-DKD, T2D-DKD \\
\hline SLC2A2 & $+16459 \mathrm{C} / \mathrm{T}$ & T1D-DKD \\
\hline SUMO4 & rs237025 & T2D-DKD \\
\hline SUV39H2 & rs17353856 & T1D-DKD \\
\hline TCF7L2 & rs7903146 & T2D-DKD \\
\hline$T G F \beta 1$ & rs1800470 & T1D-DKD, T2D-DKD \\
\hline THP & rs12444268 & T1D-DKD \\
\hline TMPO & rs4762495 & T1D-ESRD \\
\hline$T N F \alpha$ & rs1800629, rs1800470, rs1800469, rs1800630, rs1799964 & T2D-DKD, T2D-ESRD \\
\hline TRAF6 & rs16928973 & T2D-DKD \\
\hline TRIB3 & rs2295490 & T2D-DKD \\
\hline UMOD & rs12917707, rs13333226 & T2D-DKD \\
\hline$V D R$ & Raql variant & T2D-DKD \\
\hline VEGF & $-1499 \mathrm{C} / \mathrm{T}, \mathrm{rs} 2010963$ & T1D-DKD, T2D-DKD \\
\hline VEGFA & rs3025021 & T1D-DKD \\
\hline WNT4/ZBTB4O & rs12137135 & T1D-ESRD \\
\hline ZMIZ1 & rs1749824 & T1D-ESRD \\
\hline miRNA-146a & rs2910164 & T1D-DKD, T2D-DKD \\
\hline miRNA-125 & rs12976445 & T2D-DKD \\
\hline
\end{tabular}


which is important for electrolyte homeostasis. Mutations in this gene are characterized by hypokalemic alkalosis combined with hypomagnesemia, low urinary calcium, but increased renin activity. Tanaka et al. (2003) performed a GWAS in Japanese T2D subjects and reported that the SLC12A3 Arg913Gln polymorphism was associated with reduced risk of DKD. Nishiyama et al. (2005) then conducted another 10-year longitudinal study in the same population. The results confirmed that the $913 \mathrm{Gln}$ allele of SLC12A3 Arg913Gln polymorphism conferred a protective effect in DKD (Nishiyama et al., 2005). More recently, Abu Seman et al. (2014) performed a further genetic study of SLC12A3 polymorphisms in a Malaysian population, including the meta-analysis of the association between the SLC12A3 Arg913Gln polymorphism and DKD from all the previous studies. SLC12A3 Arg913Gln polymorphism was found to be associated with T2D ( $P=0.028, \mathrm{OR}=0.772,95 \%$ $\mathrm{CI}=0.612-0.973)$ and $\mathrm{DKD}(P=0.038, \mathrm{OR}=0.547,95 \%$ $\mathrm{CI}=0.308-0.973)$ in the Malaysian cohort. The meta-analysis confirmed the protective effects of the SLC12A3 913Gln allele in $\mathrm{DKD}(\mathrm{Z}$-value $=-1.992, P=0.046, \mathrm{OR}=0.792)$. In addition, the authors investigated the role of $\operatorname{slc} 12 a 3$ expression in the progress of $\mathrm{DKD}$ with $\mathrm{db} / \mathrm{db}$ mice and in kidney development with zebrafish embryos. With knockdown of zebrafish ortholog, slc12a3 led to structural abnormality of kidney pronephric distal duct at 1-cell stage. Slc12a3 mRNA and protein expression levels were upregulated in kidneys of $\mathrm{db} / \mathrm{db}$ mice from 6,12 , and 26 weeks at the age. The authors thus concluded that SLC12A3 is a susceptibility gene in DKD, while allele 913Gln but not allele Arg913 has a preventive effect in the disease (Abu Seman et al., 2014). This association of the SLC12A3

TABLE 2B | Current data from genetic association studies in diabetic kidney disease by using genome wide association approach.

\begin{tabular}{|c|c|c|c|c|}
\hline Gene symbol & Genomic DNA polymorphisms & $P$-value & Disease & References \\
\hline AFF3 & rs7583877, rs7562121 & $\begin{array}{l}P=1.2 \times 10(-8) \text { and } \\
<1 \times 10(-6)\end{array}$ & T1D-ESRD & Sandholm et al., 2012, 2017 \\
\hline AGER & rs2070600, rs2071288 & $P<0.001$ & T2D-DKD & Lim et al., 2017 \\
\hline AGTR1 & rs12695897 & $P=0.032$ & T2D-ESRD & Palmer et al., 2014 \\
\hline APOL1 & rs136161, rs713753, rs767855 & $P=0.006-0.037$ & T2D-ESRD & Palmer et al., 2014 \\
\hline$B I D$ & rs181390 & $P=0.006$ & T1D-ESRD & Craig et al., 2009 \\
\hline CARS & rs452041, rs739401 & $P=3.1 \times 10(-6)$ & T1D-DKD, T2D-DKD & Pezzolesi et al., 2009b \\
\hline CERS2 & rs267734, rs267738 & $P=0.0013$ and 0.0015 & T1D-DKD, T2D-DKD & Shiffman et al., 2014 \\
\hline CDCA7-SP3 & rs4972593 & $P=5 \times 10(-8)$ & T1D-ESRD in women & Sandholm et al., 2013 \\
\hline CHN2 & rs17157914 & $P=0.029$ & T2D-ESRD & Palmer et al., 2014 \\
\hline CNDP1 & rs4892249, rs6566815 & $P=0.0043$ and 0.0076 & T2D-ESRD & Palmer et al., 2014 \\
\hline ERBB4 & rs7588550 & $P=2.1 \times 10(-7)$ & T1D-DKD & Sandholm et al., 2012 \\
\hline FRMD3 & $\begin{array}{l}\text { rs942278, rs1888747, rs10868025, } \\
\text { rs942280, rs942263, rs1535753, } \\
\text { rs2378658, rs13288659 }\end{array}$ & $P=5.0 \times 10(-7)$ & T1D-ESRD, T2D-ESRD & $\begin{array}{l}\text { Pezzolesi et al., 2009a; } \\
\text { Freedman et al., } 2011\end{array}$ \\
\hline GABRR1 & rs9942471 & $P=4.5 \times 10(-8)$ & T2D-DKD & van Zuydam NR \\
\hline GCKR & rs1260326 & $P=3.23 \times 10(-3)$ & T2D-eGFR & Deshmukh et al., 2013 \\
\hline GLRA3 & rs1564939 & $P=0.0013$ & T1D-AER & Sandholm et al., 2018 \\
\hline KLKB & rs4253311 & $P=5.5 \times 10(-8)$ & Plasma renin activity & Lieb et al., 2015 \\
\hline KNG1 & rs5030062 & $P=0.001$ & Plasma renin activity & Lieb et al., 2015 \\
\hline LIMK2 & rs2106294, rs4820043 & $P=7.49 \mathrm{E}-04$ and 0.001 & T2D-ESRD & McDonough et al., 2011 \\
\hline MMP9 & rs481480, rs2032487, rs4281481 & $\begin{array}{l}P=0.038,0.045 \text { and } 0.048 \\
P=0.053,0.054 \text { and } 0.055\end{array}$ & T2D-ESRD T2D-DKD & $\begin{array}{l}\text { Freedman et al., 2009; Cooke } \\
\text { et al., } 2012\end{array}$ \\
\hline RPS12 & rs9493454 & $P=8.79 \times 10(-4)$ & T2D-ESRD & McDonough et al., 2011 \\
\hline SHROOM3 & rs1739721 & $P=3.18 \times 10(-3)$ & T2D-eGFR & Deshmukh et al., 2013 \\
\hline
\end{tabular}


TABLE 2B | Continued

\begin{tabular}{lllll}
\hline Gene symbol & Genomic DNA polymorphisms & $\boldsymbol{P}$-value & Disease & References \\
\hline SLC12A3 & rs11643718 & $P=0.021$ & T2D-DKD, T2D-ESRD & Tanaka et al., 2003 \\
TMPO & rs4762495 & $P=0.0006$ & T1D-ESRD & Craig et al., 2009 \\
UMOD & rs12917707 & $P=8.84 \times 10(-4)$ & T2D-eGFR & Deshmukh et al., 2013 \\
ZMIZ1 & rs1749824 & $P=8.1 \times 10(-5)$ & T1D-ESRD & Craig et al., 2009
\end{tabular}

Data were extracted from more than 300 references in PubMed and most studies were carryout with genetic association study of candidate gene(s). CNVs, Copy Number Variants; DKD, Diabetic Kidney Disease; eGFR, estimated Glomerular Filtration Rate; T1D, Type 1 Diabetes Mellitus; T2D, Type 2 Diabetes Mellitus; ABCG, ATP Binding Cassette Subfamily G; ACACB, Acetyl-CoA Carboxylase Beta; ACE, Angiotensin I Converting Enzyme; ADPOQ, Adiponectin; ADRB2, Adrenoceptor Beta 2; AFF3, AF4/FMR2 Family Member 3; AGER, Advanced Glycosylation End-Product Specific Receptor; AGT, Angiotensinogen; AGTR, Angiotensin II Receptor; AKR1B1, Aldo-Keto Reductase Family 1 Member B; ALOX12, Arachidonate 12-Lipoxygenase, 12S Type; ApoE, Apolipoprotein E; APOL1, Apolipoprotein L1; AUH, AU RNA Binding Methylglutaconyl-CoA Hydratase; BID, BH3 Interacting Domain Death Agonist; CALD1, Caldesmon 1; CaSR, Calcium-Sensing Receptor; CARS, Cysteinyl-TRNA Synthetase; CAT, Catalase; CERS2, Ceramide Synthase 2; CDCA7, Cell Division Cycle Associated 7; CDH13, Cadherin 13; CHN2, Chimerin 2; CNDP, Carnosine Dipeptidase; COQ5, Coenzyme Q5, Methyltransferase; COX6A1, Cytochrome C Oxidase Subunit 6A1; COX10, COX10, Heme A:Farnesyltransferase Cytochrome C Oxidase Assembly Factor; CUBN, Cubilin; CYBA, Cytochrome B-245 Alpha Chain; CYP11B2, Cytochrome P450 Family 11 Subfamily B Member 2; ELMO1, Engulfment And Cell Motility 1; eNOS, Nitric Oxide Synthase; ENPP1, Ectonucleotide Pyrophosphatase/Phosphodiesterase 1; EPO, Erythropoietin; EPHX2, Epoxide Hydrolase 2; ERBB4, Erb-B2 Receptor Tyrosine Kinase 4; ESR1, Estrogen Receptor 1; FRMD3, FERM Domain Containing 3; FNDC5, Fibronectin Type III Domain Containing 5; GAS6, Growth Arrest Specific 6; GATC, Glutamyl-TRNA Amidotransferase Subunit C; GCK, Glucokinase; GCKR, Glucokinase Regulator; GFPT2, GlutamineFructose-6-Phosphate Transaminase 2; GLRA3, Glycine Receptor Alpha 3; GPX1, Glutathione Peroxidase 1; GREM1, Gremlin 1, DAN Family BMP Antagonist; GSTP1, Glutathione S-Transferase Pi 1; HIF1a, Hypoxia Inducible Factor 1 Subunit Alpha; H19, H19, Imprinted Maternally Expressed Transcript; HMGA2, High Mobility Group AT-Hook 2; HO1. Heme Oxygenase 1; HSP70, Heat Shock Protein 70; ICAM1, Intercellular Adhesion Molecule 1; IGF2, Insulin Like Growth Factor 2; IGFBP1, Insulin Like Growth Factor Binding Protein 1; IL, Interleukin; IRAK4, Interleukin 1 Receptor Associated Kinase 4; INSR, Insulin Receptor; IRS2, Insulin Receptor Substrate 2; KCNQ1, Potassium Voltage-Gated Channel Subfamily Q Member 1; KLRA1, Killer Cell Lectin Like Receptor A1; KNG1, Kininogen 1; LTA, Lymphotoxin Alpha; LIMK2, LIM Domain Kinase 2; MAPRE1P2, MAPRE1 Pseudogene 2; MCF2L2, MCF.2 Cell Line Derived Transforming Sequence-Like 2; MGP, Matrix Gla Protein; MME, Membrane Metalloendopeptidase; MMP, Matrix Metallopeptidase; MSC, Musculin; MTHFR, Methylenetetrahydrofolate Reductase; MT2A, Metallothionein 2A; MSRB3, Methionine Sulfoxide Reductase B3; MTOR, Mechanistic Target of Rapamycin Kinase; MyD88, Myeloid Differentiation Primary Response 88; MYH9, Myosin Heavy Chain 9; NCALD, Neurocalcin Delta; NOS, Nitric Oxide Synthase; NQO1, NAD(P)H Quinone Dehydrogenase 1; NPHS1, NPHS1, Nephrin; NPY, Neuropeptide Y; PACRG, Parkin Coregulated; PAl1, Plasminogen Activator Inhibitor 1; PARK2, Parkin RBR E3 Ubiquitin Protein Ligase; PFKFB2, 6-Phosphofructo-2-Kinase/Fructose2,6-Biphosphatase 2; PLXDC2, Plexin Domain Containing 2; PLEKHH2, Pleckstrin Homology, MyTH4 and FERM Domain Containing H2; PON, Paraoxonase; PPARG, Peroxisome Proliferators-Activated Receptor Gamma; PPARGC1A, Peroxisome Proliferators-Activated Receptor Gamma Co-activator 1 alpha; PRKAA2, Protein Kinase AMP-Activated Catalytic Subunit Alpha 2; PROX1, Prospero Homeobox 1; PSMD9, Proteasome 26S Subunit, Non-ATPase 9; PRKCB1, Protein Kinase C Beta; PTX3, Pentraxin 3; PVT1, Pvt1 Oncogene; RAGE, Advanced Glycosylation End-Product Specific Receptor; RAET1L, Retinoic Acid Early Transcript 1L; RBP4, Retinol Binding Protein 4; REN, Renin; RGMA, Repulsive Guidance Molecule BMP Co-Receptor A; RREB1, Ras Responsive Element Binding Protein 1; TOP1MT, DNA Topoisomerase I Mitochondrial; RPS12, Ribosomal Protein S12; RTN1, Reticulon 1; SASH1, SAM And SH3 Domain Containing 1; SCAF8, SR-Related CTD Associated Factor 8; SEMA6D, Semaphorin 6D; SERPINB, Serpin Family; SHROOM3, Shroom Family Member 3; SIK1, Salt Inducible Kinase 1; SIRT1, Sirtuin 1; SLC2A, Solute Carrier Family 2; SLC12A3, Solute Carrier Family 12 Member 3; SOD, Superoxide Dismutase; SOX2, SRY-Box 2; SORBS1, Sorbin and SH3 Domain Containing 1; SP3, Sp3 Transcription Factor; SUMO4, Small Ubiquitin-Like Modifier 4; SUV39H2, Suppressor Of Variegation 3-9 Homolog 2; TCF7L2, Transcription Factor 7 Like 2; TGF 1 , Transforming Growth Factor Beta 1; TMPO, Thymopoietin; TNFa, Tumor Necrosis Factor alpha; THP, Tamm-Horsfall protein; TRAF6, TNF Receptor Associated Factor 6; TRIB3, Tribbles Pseudokinase 3; UMOD, Uromodulin; VEGF, Vascular Endothelial Growth Factor; VEGFA, Vascular Endothelial Growth Factor A; VDR, Vitamin D Receptor; WNT4, Wnt Family Member 4; ZBTB40, Zinc Finger and BTB Domain Containing 40; ZMIZ1, Zinc Finger MIZ-Type Containing 1.

Arg913Gln polymorphism with DKD has been very recently replicated in a Chinese population (Zhang et al., 2018). The $U M O D$ gene encoded glycoprotein is synthesized exclusively in renal tubular cells and released into urine. Furthermore, UMOD may prevent urinary tract infection and inhibit formation of liquid containing supersaturated salts and subsequent formation of salt crystals. SNPs rs4293393 and rs1297707 in the UMOD gene are found to be associated with the susceptibility to DKD in T2D (Ahluwalia et al., 2011a; Prudente et al., 2017; van Zuydam et al., 2018).

The Human Genome Project has revealed that there are more than twenty thousand protein coding genes, and probably more than one million of RNA genes ${ }^{6}$. Genetic association studies of RNA gene polymorphisms with DKD are very limited. Up to date, only two SNPs, i.e., rs2910164 and rs12976445 in the genes for miRNA-146a and miRNA-125 have been found to be associated with DKD in T1D and T2D (Li et al., 2014; Kaidonis et al., 2016). Further investigation of RNA genetic variation conferring susceptibility to DKD needs to be undertaken.

${ }^{6} \mathrm{https} / /$ www.genecards.org/

\section{CURRENT INFORMATION FROM EPIGENETIC STUDIES IN DIABETIC KIDNEY DISEASE}

Similar to genetic association studies, epigenome-wide (EWAS) and candidate gene DNA methylation analyses have been used for epigenetic studies of DKD. Current information from epigenetic studies in DKD are represented in Table 3. An EWAS suggested that several genes, including SLC22A12, TRPM6, $A Q P 9, H P, A G T X$, and HYAL2, may have epigenetic effects in DKD (VanderJagt et al., 2015). Interestingly, SLC22A12 encodes for urate anion transporter 1 (URAT1), which is a kidney-specific urate transporter that transports urate across the apical membrane of the proximal tubule in kidneys. Loss-of-function SLC22A12 mutations are associated with renal hypouricaemia and affected persons can develop exercise-induced acute kidney injury and are at increased risk of developing urate stones (Lee et al., 2008). TRPM6 is a member of transient receptor potential superfamily of cation channels. This gene is widely expressed in the body, including kidneys along the nephron. The TRPM6 
TABLE 3 | Current information from epigenetic studies in diabetic kidney disease.

\begin{tabular}{|c|c|c|c|c|}
\hline Analysis & Gene symbol/ Target & Material and methods & Results & References \\
\hline \multirow[t]{23}{*}{ DNA methylation } & AKR1B1, TIMP-2 & T2DM-DKD & $\begin{array}{l}\text { Hypomethylation of the genes are } \\
\text { associated with albuminuria }\end{array}$ & Aldemir et al., 2017 \\
\hline & AKR1B1, IGF1, SLC12A3 & T2DM-DKD and ESRD & $\begin{array}{l}\text { Those genes implicated in DKD } \\
\text { based upon the inter-individual } \\
\text { epigenetic differences }\end{array}$ & Sapienza et al., 2011 \\
\hline & CTGF & $\begin{array}{l}\text { T2DM-DKD Glomerular and } \\
\text { mesangial cells }\end{array}$ & $\begin{array}{l}\text { Hypomethylation through the } \\
\text { decreased Dnmt3a binding in the } \\
\text { gene promoter }\end{array}$ & Zhang et al., 2014 \\
\hline & IGFBP1 & T1DM-DKD & Hypermethylation & Gu et al., 2014 \\
\hline & IL13RA1, IL15, EDG3, INHA & $\begin{array}{l}\text { Hemodialyzed patients with } \\
\text { DKD }\end{array}$ & Hypermethylation & Korabecna et al., 2013 \\
\hline & MTHFR & $\begin{array}{l}\text { Diabetic complications, } \\
\text { including DKD }\end{array}$ & Hypermethylation & Dos Santos Nunes et al., 2018 \\
\hline & MTHFR & T2DM-DKD & Demethylation & Yang et al., 2016 \\
\hline & MIOX & Human and mouse & Hypomethylation & Sharma et al., 2017 \\
\hline & PIK3C2B & Glomeruli in DKD & $\begin{array}{l}\text { Up-regulated with methylation in } \\
\text { glomeruli }\end{array}$ & Wang et al., 2018 \\
\hline & POLR2G, DDB1, ZNF230 & & $\begin{array}{l}\text { Down-regulated with methylation in } \\
\text { glomeruli }\end{array}$ & \\
\hline & SLC30A8 & T2DM-DKD & Hypermethylation & Seman et al., 2015 \\
\hline & $\begin{array}{l}\text { SLC22A12, TRPM6, AQP9, } \\
\text { HP, AGXT, HYAL2 }\end{array}$ & Pre-diabetes and T2DM-DN & $\begin{array}{l}\text { Hypermethylation found in } 174 \text { of } \\
694 \text { CpG sites }\end{array}$ & VanderJagt et al., 2015 \\
\hline & $\begin{array}{l}\text { TAMM41, PMPCB, TSFM, } \\
\text { AUH }\end{array}$ & T1DM-DKD & $\begin{array}{l}\text { DNA methylation changes in these } \\
\text { genes and influence with } \\
\text { mitochondrial function }\end{array}$ & Swan et al., 2015 \\
\hline & UNC13B & T1DM-DKD & $\begin{array}{l}\text { An intronic polymorphism } \\
\text { rs13293564 in the gene is } \\
\text { associated with DKD DNA } \\
\text { methylation levels in } 19 \text { CpG sites } \\
\text { are changed }\end{array}$ & Bell et al., 2010 \\
\hline & $K L F 4$ & $\begin{array}{l}\text { Glomerular podocytes in } \\
\text { human and mouse }\end{array}$ & $\begin{array}{l}\text { DNA methylation levels in the } \\
\text { promoters of genes encoding } \\
\text { mesenchymal markers are } \\
\text { increased }\end{array}$ & Hayashi et al., 2014 \\
\hline & $a P C$ & Podocytes & $\begin{array}{l}\text { aPC epigenetically controls } \\
\text { p66(Shc) expression }\end{array}$ & Bock et al., 2013 \\
\hline & egfr & $\begin{array}{l}\text { Cultured proximal tubule } \\
\text { (normal rat kidney) cells }\end{array}$ & $\begin{array}{l}\text { Inhibition of histone deacetylase in } \\
\text { eGFR }\end{array}$ & Gilbert et al., 2011 \\
\hline & $p \times r$ & $\begin{array}{l}\mathrm{db} / \mathrm{db} \text { mice and proximal } \\
\text { tubular cells }\end{array}$ & Demethylation of DNA & Watanabe et al., 2018 \\
\hline & $d n m t 1$ & $\mathrm{db} / \mathrm{db}$ mice & Hypomethylation & Zhang et al., 2017 \\
\hline & agt, abcc4, cyp4a10, glut5 & $\mathrm{db} / \mathrm{m}$ mouse & Hypomethylation & Marumo et al., 2015 \\
\hline & kif20b, cldn18, slco1a1 & & Hypomethylation & \\
\hline & sglt2, pck1, g6pc, hnf4a & $\mathrm{db} / \mathrm{db}$ mice & $\begin{array}{l}\text { Demethylated in the proximal } \\
\text { tubules }\end{array}$ & Marumo et al., 2015 \\
\hline & $\operatorname{tgfb} 1$, tet2 & $\mathrm{db} / \mathrm{db}$ mice & Decreased DNA methylation & Yang et al., 2018 \\
\hline \multirow[t]{3}{*}{$\begin{array}{l}\text { Histone } \\
\text { modification }\end{array}$} & MTHFR & T2D with DN & $\begin{array}{l}\text { MTHFR regulates histone } \\
\text { modification rs } 1801133 \text { C677T in } \\
\text { the gene is associated with DN }\end{array}$ & Zhou et al., 2015 \\
\hline & TGFB1 & Glomerular and mesangial cells & $\begin{array}{l}\text { TGF- } \beta 1 \text { increases expression of the } \\
\text { H3K } 4 \text { methyltransferase SET7/9 }\end{array}$ & Sun et al., 2010 \\
\hline & 12/15-LO & Glomerular and mesangial cells & $\begin{array}{l}\text { Up-regulation of histone lysine } \\
\text { modifications }\end{array}$ & Yuan et al., 2016 \\
\hline
\end{tabular}


TABLE 3 | Continued

\begin{tabular}{|c|c|c|c|c|}
\hline Analysis & Gene symbol/ Target & Material and methods & Results & References \\
\hline & h3k9/14ac, at1r & $\begin{array}{l}\text { Glomerular and mesangial cells } \\
\mathrm{db} / \mathrm{db} \text { mice }\end{array}$ & $\begin{array}{l}\text { Losartan attenuated increased } \\
\text { H3K9/14Ac at RAGE, PAI- } 1 \text { and } \\
\text { MCP-1 promoters, while the } \\
\text { chromatin state at these genes are } \\
\text { mediated in part by AT1R }\end{array}$ & Reddy et al., 2014 \\
\hline & $h 3 k 9, h 3 k 23$ & $\mathrm{db} / \mathrm{db}$ and $\mathrm{C} 57 \mathrm{BL} / 6$ mice & Acetylation & Sayyed et al., 2010 \\
\hline & $h 3 k 4$ in serine 10 & & Demethylation and phosphorylation & \\
\hline & h3k9/14ac & $\mathrm{db} /+$ mice & $\begin{array}{l}\text { Losartan reversed permissive } \\
\text { epigenetic changes in renal } \\
\text { glomeruli }\end{array}$ & Reddy et al., 2014 \\
\hline & set7/9 & $\mathrm{db} / \mathrm{db}$ mice & $\begin{array}{l}\text { Induced histone modification and } \\
\text { mcp-1 expression }\end{array}$ & Chen et al., 2014 \\
\hline & $x b p 1$ & $\mathrm{db} / \mathrm{db}$ mice & $\begin{array}{l}\text { XBP1s-mediated of histone SET7/9 } \\
\text { and consequently decreased } \\
\text { MCP-1 expression }\end{array}$ & Chen et al., 2014 \\
\hline & opn/h3k27me3 & Sur1-E1506K mice & Histone modification with opn & Cai et al., 2016 \\
\hline & $\begin{array}{l}\text { txnip, h3k9ac, h3k4me3, } \\
\text { h3k4me1, h3k27me3 }\end{array}$ & Sur1-E1506K mice & Histone acetylation changes & De Marinis et al., 2016 \\
\hline & egfr & $\begin{array}{l}\text { Cultured proximal tubule } \\
\text { (normal rat kidney) cells }\end{array}$ & $\begin{array}{l}\text { Inhibition of histone deacetylase in } \\
\text { eGFR }\end{array}$ & Gilbert et al., 2011 \\
\hline & grp78/histone h4 & Diabetic rats & Acetylation changes & Sun et al., 2016 \\
\hline & $m f n 2$ & Diabetic rats & $\begin{array}{l}\text { Histone acetylation at collagen IV } \\
\text { promoter }\end{array}$ & Mi et al., 2016 \\
\hline & $\begin{array}{l}\text { h3 and hsp-27, map kinase } \\
\text { p28 }\end{array}$ & Sprague-Dawley rats & $\begin{array}{l}\text { Dephosphorylation and acetylation } \\
\text { of h3 }\end{array}$ & Tikoo et al., 2008 \\
\hline \multirow{5}{*}{$\begin{array}{l}\text { Non-coding RNA } \\
\text { dysregulation }\end{array}$} & miR-9-3, miR34a, miR-137 & DKD and diabetic retinopathy & DNA methylation changes & Dos Santos Nunes et al., 2018 \\
\hline & miR-199b-5p, klotho & T2DM-DKD and STZ mice & $\begin{array}{l}\text { Increased serum klotho levels are } \\
\text { mediated by miR-199b-5p }\end{array}$ & Kang and Xu, 2016 \\
\hline & microRNA Let-7a-3 & T2DM with DKD & $\begin{array}{l}\text { DNA methylation levels in the } \\
\text { promoter are increased by targeting } \\
\text { UHRF1 }\end{array}$ & Peng et al., 2015 \\
\hline & microRNA 1207-5P & Glomerular and mesangial cells & $\begin{array}{l}\text { This PVT1-derived microRNA is } \\
\text { upregulated by glucose and } \\
\text { TGF- } \beta 1\end{array}$ & Alvarez et al., 2013 \\
\hline & creb1, miR-10a & HFD/STZ mice & $\begin{array}{l}\text { This microRNA regulate epigenetic } \\
\text { modification by targeting creb1 }\end{array}$ & Shan et al., 2016 \\
\hline
\end{tabular}

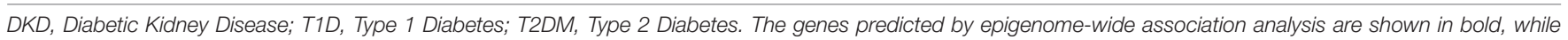

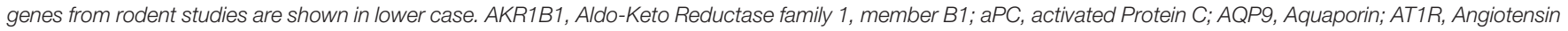

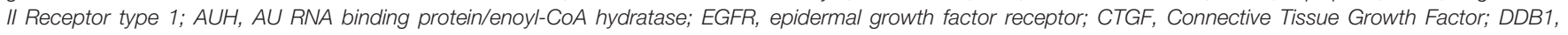

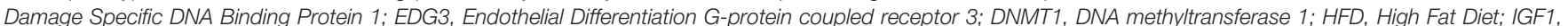

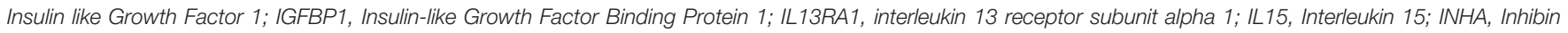

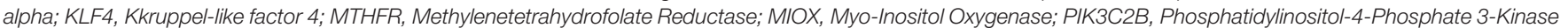

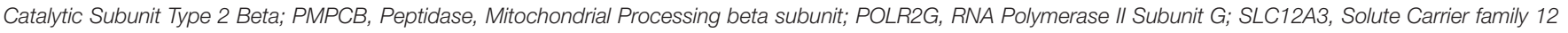

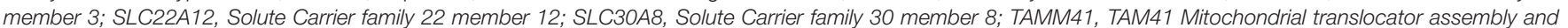

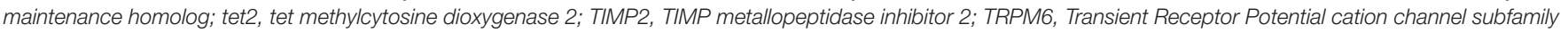

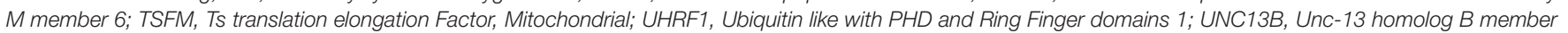
3; XBP1, X-Box Binding Protein 1; ZNF230, Zinc Finger Protein 230; 12/15-LO, 12/15-lipoxygenase; TGFB1, Transforming Growth Factor Beta 1.

channels are mainly located in the renal distal convoluted tubule, the site of active transcellular calcium and magnesium transport in the kidney (Felsenfeld et al., 2015). As described previously, several studies have implicated UMOD genetic polymorphisms in the susceptibility to DKD (Ahluwalia et al., 2011a; Prudente et al., 2017; van Zuydam et al., 2018). A recent study has demonstrated that UMOD regulates renal magnesium homeostasis through TRPM6 (Nie et al., 2018). Furthermore, analyses of the candidate genes such as IGFBP1 and MTHFR have also provided evidence that
DNA methylation changes in these genes may be involved in the pathogenesis of DKD (Gu et al., 2013, 2014; Yang et al., 2016). Combining and analyzing data from genetic and epigenetic studies together may help understand some of the pathophysiology in DKD.

ncRNAs regulate gene expression at the post-transcriptional level and are involved in chromatin histone modification. Most of studies concerning histone modification and ncRNA dysregulation have been performed in diabetic animal models, while a few studies have been undertaken in subjects with 
DKD (Table 3). Reddy et al. (2014) have analyzed histone modification profiles in genes associated with DKD pathology and the modified regulation of these genes following treatment with the angiotensin II type 1 receptor (AT1R) blocker losartan. The data indicate that losartan attenuates key parameters of DKD and modifies gene expression, and reverses some epigenetic changes in $\mathrm{db} / \mathrm{db}$ mice. Losartan also attenuates increased $\mathrm{H} 3 \mathrm{~K} 9 / 14 \mathrm{Ac}$ at RAGE, PAI-1, and MCP-1 promoters in mesangial cells cultured under diabetic conditions (Reddy et al., 2014). In a recent study of subjects of T2D and diabetic complications (including DKD) (Dos Santos Nunes et al., 2018) the methylation profiles of $\mathrm{miR}$ gene were compared and related to the presence of diabetic complications. Results indicated that miRs can modulate the expression of a variety of genes and methylation changes of $m i R$ 9-3, $m i R-34 a$, and $m i R-137$ were found to be associated with diabetic complications (Dos Santos Nunes et al., 2018). These two studies provide evidence suggesting that therapies targeting epigenetic regulators might be beneficial in the treatment of DKD.

\section{SUMMARY AND PERSPECTIVES}

Researchers have made major efforts to undertake well powered genetic and epigenetic studies in DKD to help understand its pathogenesis. The data, however, need to be confirmed by several strategies, for instance, replication studies could be performed with better selection of subjects with similar genetic background to limit influences from migration; intermarriage; cultural preferences; coupled with further investigation of DNA variation and methylation changes in RNA regulation genes and biological experiments to determine functional impact of these variants. Furthermore, new technologies for DNA and ncRNA sequencing analysis such as third generation sequencing and a PheWAS approach have recently been developed.

\section{New Generation Sequencing}

DNA sequencing analysis is used for determining the accurate order of nucleotides along chromosomes and genomes. Secondgeneration sequencing, commonly known as next-generation sequencing (NGS), has presently become popular in DNA sequencing analysis because NGS can enable a massivelyparalleled approach capable of producing large numbers of reads at high coverages along the genome and therefore dramatically reduce the cost of DNA sequencing analysis (Treangen and Salzberg, 2011; Gu et al., 2018; Mone et al., 2018). Today, third-generation sequencing (often called as longread sequencing) is a new generation sequencing method, which works by reading the nucleotide sequences at single molecule level in contrast to the first and second generations of DNA sequencing (van Dijk et al., 2018). Moreover, it is necessary to develop the molecular instruments for whole genome sequencing to make this new generation sequencing commercially available. The advanced sequencing technologies will improve genetic and epigenetic studies in DKD in the near future.

\section{ncRNA Genetic and Epigenetic Studies}

In the human genome, RNA genes are much more abundant than protein coding genes, while ncRNAs mainly include miRNAs and lncRNAs. Both forms of ncRNAs have been found to be involved in chromatin histone modifications, and subsequently can have epigenetic effects on the target genes. Therefore, identification of RNA genetic variation and investigation of biological alteration of these RNA genes should be included in research plans. Kato has very recently pointed out a hypothesis that transforming growth factor- $\beta$ (TGF1 $\beta$ ) may play an important role in early stage development of DKD, while some miRNAs and lncRNAs regulate the key molecules in the TGF1 $\beta$ pathway. These ncRNAs may be served as biomarkers for predicting the potential targets for prevention and treatment in DKD (Kato, 2018). Furthermore, Smyth et al. (2018) have compared Sanger sequencing and NGS to validate the five top ranked miRNAs that are predicted to be associated with DKD by EWAS. This study suggests that targeted NGS may offer a more cost-effective and sensitive approach and implied that the methylated miR329-2, in which region SNP rs10132943 is located, and miR-429 where SNPs rs7521584 and rs112695918 exist, are associated with DKD (Smyth et al., 2018). Although these two studies are preliminary, they may be good examples to help direct further DKD research.

\section{Phenome-Wide Association Study (PheWAS)}

PheWAS is a new approach to analyze many phenotypes in comparison with a single genetic variant. This approach was originally described using electronic medical record (EMR) data from EMR-linked with a DNA biobank and also can be combined with GWAS and EWAS. Therefore, PheWAS has become a powerful tool to investigate the impact of genetic variation on drug response among many individuals and may expand our knowledge of new drug targets and effects (Pendergrass and Ritchie, 2015; Denny et al., 2016; Roden, 2017). Clearly, combined with GWAS and EWAS, PheWAS will provide us with the possibility to discover the associations with drug effects, including therapeutic response and side effect profiles in DKD (Hebbring, 2014).

Taken together, application of these advanced studies in DKD will be very useful not only for evaluating current data from genetic and epigenetic studies but also for generating new knowledge for dissecting the complexity of this disease.

\section{AUTHOR CONTRIBUTIONS}

The author confirms being the sole contributor of this work and has approved it for publication.

\section{FUNDING}

The study was supported by the Start Grant from China Pharmaceutical University. 


\section{REFERENCES}

Abu Seman, N., He, B., Ojala, J. R., Wan Mohamud, W. N., Östenson, C. G., Brismar, K., et al. (2014). Genetic and biological effects of sodium-chloride cotransporter (SLC12A3) in diabetic nephropathy. Am. J. Nephrol. 40, 408-416. doi: $10.1159 / 000368916$

Ahluwalia, T. S., Khullar, M., Ahuja, M., Kohli, H. S., Bhansali, A., Mohan, V., et al. (2009). Common variants of inflammatory cytokine genes are associated with risk of nephropathy in type 2 diabetes among Asian Indians. PLoS One 4:e5168. doi: 10.1371/journal.pone.0005168

Ahluwalia, T. S., Lindholm, E., Groop, L., and Melander, O. (2011a). Uromodulin gene variant is associated with type 2 diabetic nephropathy. J. Hypertens. 29, 1731-1734. doi: 10.1097/HJH.0b013e328349de25

Ahluwalia, T. S., Lindholm, E., and Groop, L. C. (2011b). Common variants in CNDP1 and CNDP2, and risk of nephropathy in type 2 diabetes. Diabetologia 54, 2295-2302. doi: 10.1007/s00125-011-2178-5

Alberto Ramirez-Garcia, S., Charles-Niño, C., Mazariegos-Rubí, M., Rosalba Topete-González, L., Topete-González, R., Javier Flores-Alvarado, L., et al. (2015). Association of the ELMO1 gene (snp rs1345365) with development of type 2 diabetes mellitus in the Mexican mestizo population. Invest. Clin. 56, 341-355.

Albrecht, T., Schilperoort, M., Zhang, S., Braun, J. D., Qiu, J., Rodriguez, A., et al. (2017a). Carnosine attenuates the development of both type 2 diabetes and diabetic nephropathy in BTBR ob/ob mice. Sci. Rep. 7:44492. doi: 10.1038/ srep44492

Albrecht, T., Zhang, S., Braun, J. D., Xia, L., Rodriquez, A., and Qiu, J. (2017b). The CNDP1 (CTG)(5) polymorphism is associated with biopsy-proven diabetic nephropathy, time on hemodialysis, and diabetes duration. J. Diabetes Res. 2017:9506730. doi: 10.1155/2017/9506730

Aldemir, O., Turgut, F., and Gokce, C. (2017). The association between methylation levels of targeted genes and albuminuria in patients with early diabetic kidney disease. Ren. Fail. 39, 597-601. doi: 10.1080/0886022X.2017.1358180

Alkhalaf, A., Bakker, S. J., Bilo, H. J., Gans, R. O., Navis, G. J., Postmus, D., et al. (2010). A polymorphism in the gene encoding carnosinase (CNDP1) as a predictor of mortality and progression from nephropathy to end-stage renal disease in type 1 diabetes mellitus. Diabetologia 53, 2562-2568. doi: 10.1007/ s00125-010-1863-0

Allis, C. D., and Jenuwein, T. (2016). The molecular hallmarks of epigenetic control. Nat. Rev. Genet. 17, 487-500. doi: 10.1038/nrg.2016.59

Alvarez, M. L., Khosroheidari, M., Eddy, E., and Kiefer, J. (2013). Role of microRNA 1207-5P and its host gene, the long non-coding RNA Pvtl, as mediators of extracellular matrix accumulation in the kidney: implications for diabetic nephropathy. PLoS One 8:e77468. doi: 10.1371/journal.pone.0077468

Al-Waheeb, S., Alwohhaib, M., Abdelghani, A., Al-Sharrah, S., Al-Shafey, E., AlSahow, A., et al. (2016). Evaluation of associations between single nucleotide polymorphisms in the FRMD3 and CARS genes and diabetic nephropathy in a Kuwaiti population. Genet. Mol. Res. 15:gmr7619. doi: 10.4238/gmr.15017619

Badal, S. S., and Danesh, F. R. (2014). New insights into molecular mechanisms of diabetic kidney disease. Am. J. Kidney Dis. 63(2 Suppl. 2), S63-S83. doi: 10.1053/j.ajkd.2013.10.047

Bailey, J. N. C., Palmer, N. D., Ng, M. C. Y., Bonomo, J. A., Hicks, P. J., Hester, J. M., et al. (2014). Analysis of coding variants identified from exome sequencing resources for association with diabetic and non-diabetic nephropathy in African Americans. Hum. Genet. 133, 769-779. doi: 10.1007/s00439-013-1415-z

Barrett, E. J., Liu, Z., Khamaisi, M., King, G. L., Klein, R., Klein, B. E. K., et al. (2017). Diabetic microvascular disease: an endocrine society scientific statement. J. Clin. Endocrinol. Metab. 102, 4343-4410. doi: 10.1210/jc.201701922

Bell, C. G., Teschendorff, A. E., Rakyan, V. K., Maxwell, A. P., Beck, S., and Savage, D. A. (2010). Genome-wide DNA methylation analysis for diabetic nephropathy in type 1 diabetes mellitus. BMC Med. Genomics 3:33. doi: 10 . 1186/1755-8794-3-33

Bock, F., Shahzad, K., Wang, H., Stoyanov, S., Wolter, J., Dong, W., et al. (2013). Activated protein $C$ ameliorates diabetic nephropathy by epigenetically inhibiting the redox enzyme p66Shc. Proc. Natl. Acad. Sci. U.S.A. 110, 648-653. doi: $10.1073 /$ pnas. 1218667110

Bodhini, D., Chidambaram, M., Liju, S., Revathi, B., Laasya, D., Sathish, N., et al. (2016). Association of rs11643718 SLC12A3 and rs741301 ELMO1 variants with diabetic nephropathy in south Indian population. Ann. Hum. Genet. 80, 336-341. doi: 10.1111/ahg.12174

Bouhairie, V. E., and McGill, J. B. (2016). Diabetic kidney disease. Mol. Med. 113, 390-394.

Cai, M., Bompada, P., Atac, D., Laakso, M., Groop, L., and De Marinis, Y. (2016). Epigenetic regulation of glucose-stimulated osteopontin (OPN) expression in diabetic kidney. Biochem. Biophys. Res. Commun. 469, 108-113. doi: 10.1016/j. bbrc.2015.11.079

Chakkera, H. A., Hanson, R. L., Kobes, S., Millis, M. P., Nelson, R. G., Knowler, W. C., et al. (2011). Association of variants in the carnosine peptidase 1 gene (CNDP1) with diabetic nephropathy in American Indians. Mol. Genet. Metab. 103, 185-190. doi: 10.1016/j.ymgme.2011.02.010

Charmet, R., Duffy, S., Keshavarzi, S., Gyorgy, B., Marre, M., Rossing, P., et al. (2018). Novel risk genes identified in a genome-wide association study for coronary artery disease in patients with type 1 diabetes. Cardiovasc. Diabetol. 17:61. doi: 10.1186/s12933-018-0705-0

Chen, J., Guo, Y., Zeng, W., Huang, L., Pang, Q., Nie, L., et al. (2014). ER stress triggers MCP-1 expression through SET7/9-induced histone methylation in the kidneys of db/db mice. Am. J. Physiol. Renal Physiol. 306, F916-F925. doi: 10.1152/ajprenal.00697.2012

Cooke, J. N., Bostrom, M. A., Hicks, P. J., Ng, M. C., Hellwege, J. N., Comeau, M. E., et al. (2012). Polymorphisms in MYH9 are associated with diabetic nephropathy in European Americans. Nephrol. Dial. Transplant. 27, 1505-1511. doi: 10.1093/ ndt/gfr522

Craig, D. W., Millis, M. P., and DiStefano, J. K. (2009). Genome-wide SNP genotyping study using pooled DNA to identify candidate markers mediating susceptibility to end-stage renal disease attributed to Type 1 diabetes. Diabet. Med. 26, 1090-1098. doi: 10.1111/j.1464-5491.2009.02846.x

Cross, S. H., and Bird, A. P. (1995). CpG islands and genes. Curr. Opin. Genet. Dev. 5, 309-314.

De Marinis, Y., Cai, M., Bompada, P., Atac, D., Kotova, O., Johansson, M. E., et al. (2016). Epigenetic regulation of the thioredoxin-interacting protein (TXNIP) gene by hyperglycemia in kidney. Kidney Int. 89, 342-353. doi: 10.1016/j.kint. 2015.12 .018

Deaton, A. M., and Bird, A. (2011). CpG islands and the regulation of transcription. Genes Dev. 25, 1010-1022. doi: 10.1101/gad.2037511

Denny, J. C., Bastarache, L., and Roden, D. M. (2016). Phenome-wide association studies as a tool to advance precision medicine. Annu. Rev. Genomics Hum. Genet. 17, 353-373. doi: 10.1146/annurev-genom-090314-024956

Deshmukh, H. A., Palmer, C. N., Morris, A. D., and Colhoun, H. M. (2013). Investigation of known estimated glomerular filtration rate loci in patients with type 2 diabetes. Diabet. Med. 30, 1230-1235. doi: 10.1111/dme.12211

Dick, K. J., Nelson, C. P., Tsaprouni, L., Sandling, J. K., Aïssi, D., Wahl, S., et al. (2014). DNA methylation and body-mass index: a genome-wide analysis. Lancet 383, 1990-1998. doi: 10.1016/S0140-6736(13)62674-4

Do, C., Shearer, A., Suzuki, M., Terry, M. B., Gelernter, J., Greally, J. M., et al. (2017). Genetic-epigenetic interactions in cis: a major focus in the post-GWAS era. Genome Biol. 18:120. doi: 10.1186/s13059-017-1250-y

Dos Santos Nunes, M. K., Silva, A. S., Wanderley de Queiroga Evangelista, I., Modesto Filho, J., Alves Pegado Gomes, C. N., Ferreira do Nascimento, R. A., et al. (2018). Analysis of the DNA methylation profiles of miR-9-3, miR-34a, and miR-137 promoters in patients with diabetic retinopathy and nephropathy. J. Diabetes Complications 32, 593-601. doi: 10.1016/j.jdiacomp.2018.03.013

Dousdampanis, P., Trigka, K., and Mouzaki, A. (2016). Tregs and kidney: from diabetic nephropathy to renal transplantation. World J. Transplant. 6, 556-563. doi: 10.5500/wjt.v6.i3.556

Felsenfeld, A. J., Levine, B. S., and Rodriguez, M. (2015). Pathophysiology of calcium, phosphorus, and magnesium dysregulation in chronic kidney disease. Semin. Dial. 28, 564-577. doi: 10.1111/sdi.12411

Feng, S., Ye, G., Bai, S., Wei, H., Liao, X., and Li, L. (2016). Matrix metalloproteinase-9 -1562C/T gene polymorphism is associated with diabetic nephropathy. Biomed Res. Int. 2016:1627143. doi: 10.1155/2016/1627143

Florez, J. C. (2016). Genetics of diabetic kidney disease. Semin. Nephrol. 36, $474-480$.

Freedman, B. I., Bostrom, M., Daeihagh, P., and Bowden, D. W. (2007a). Genetic factors in diabetic nephropathy. Clin. J. Am. Soc. Nephrol. 2, 1306-1316.

Freedman, B. I., Hicks, P. J., Bostrom, M. A., Comeau, M. E., Divers, J., Bleyer, A. J., et al. (2009). Non-muscle myosin heavy chain 9 gene $M Y H 9$ associations in 
African Americans with clinically diagnosed type 2 diabetes mellitus-associated ESRD. Nephrol. Dial. Transplant. 24, 3366-3371. doi: 10.1093/ndt/gfp316

Freedman, B. I., Hicks, P. J., Sale, M. M., Pierson, E. D., Langefeld, C. D., Rich, S. S., et al. (2007b). A leucine repeat in the carnosinase gene CNDP1 is associated with diabetic end-stage renal disease in European Americans. Nephrol. Dial. Transplant. 22, 1131-1135. doi: 10.1093/ndt/gfl717

Freedman, B. I., Langefeld, C. D., Lu, L., Divers, J., Comeau, M. E., Kopp, J. B., et al. (2011). Differential effects of MYH9 and APOL1 risk variants on FRMD3 association with diabetic ESRD in African Americans. PLoS Genet. 7:e1002150. doi: 10.1371/journal.pgen.1002150

Gilbert, R. E., Huang, Q., Thai, K., Advani, S. L., Lee, K., Yuen, D. A., et al. (2011). Histone deacetylase inhibition attenuates diabetes-associated kidney growth: potential role for epigenetic modification of the epidermal growth factor receptor. Kidney Int. 79, 1312-1321. doi: 10.1038/ki.2011.39

Gnudi, L., Coward, R. J. M., and Long, D. A. (2016). Diabetic nephropathy: perspective on novel molecular mechanisms. Trends Endocrinol. Metab. 27, 820-830. doi: 10.1016/j.tem.2016.07.002

$\mathrm{Gu}$, H. F., and Brismar, K. (2012). Genetic association studies in diabetic nephropathy. Curr. Diabetes Rev. 8, 336-344. doi: 10.2174/ 157339912802083522

Gu, T., Falhammar, H., Gu, H. F., and Brismar, K. (2014). Epigenetic analyses of the insulin-like growth factor binding protein 1 gene in type 1 diabetes and diabetic nephropathy. Clin. Epigenetics 6:10. doi: 10.1186/1868-7083-6-10

Gu, T., Gu, H. F., Hilding, A., Sjöholm, L. K., Ostenson, C. G., Ekström, T. J., et al. (2013). Increased DNA methylation levels of the insulin-like growth factor binding protein 1 gene are associated with type 2 diabetes in Swedish men. Clin. Epigenetics 5:21. doi: 10.1186/1868-7083-5-21

Gu, W., Miller, S., and Chiu, C. Y. (2018). Clinical metagenomic next-generation sequencing for pathogen detection. Annu. Rev. Pathol. [Epub ahead of print].

Guan, M., Ma, J., Keaton, J. M., Dimitrov, L., Mudgal, P., Stromberg, M., et al. (2016). Association of kidney structure-related gene variants with type 2 diabetes-attributed end-stage kidney disease in African Americans. Hum. Genet. 135, 1251-1262. doi: 10.1007/s00439-016-1714-2

Hanson, R. L., Craig, D. W., Millis, M. P., Yeatts, K. A., Kobes, S., Pearson, J. V., et al. (2007). Identification of PVT1 as a candidate gene for end-stage renal disease in type 2 diabetes using a pooling-based genome-wide single nucleotide polymorphism association study. Diabetes 56, 975-983. doi: 10.2337/db061072

Hanson, R. L., Millis, M. P., Young, N. J., Kobes, S., Nelson, R. G., Knowler, W. C., et al. (2010). ELMO1 variants and susceptibility to diabetic nephropathy in American Indians. Mol. Genet. Metab. 101, 383-390. doi: 10.1016/j.ymgme. 2010.08.014

Harjutsalo, V., and Groop, P. H. (2014). Epidemiology and risk factors for diabetic kidney disease. Adv. Chronic Kidney Dis. 21, 260-266. doi: 10.1053/j.ackd.2014. 03.009

Hathaway, C. K., Chang, A. S., Grant, R., Kim, H. S., Madden, V. J., Bagnell, C. R. Jr., et al. (2016). High Elmo1 expression aggravates and low Elmo1 expression prevents diabetic nephropathy. Proc. Natl. Acad. Sci. U.S.A. 113, 2218-2222. doi: $10.1073 /$ pnas.1600511113

Hayashi, K., Sasamura, H., Nakamura, M., Azegami, T., Oguchi, H., Sakamaki, Y., et al. (2014). KLF4-dependent epigenetic remodeling modulates podocyte phenotypes and attenuates proteinuria. J. Clin. Invest. 124, 2523-2537. doi: 10.1172/JCI69557

Hebbring, S. J. (2014). The challenges, advantages and future of phenome-wide association studies. Immunology 141, 157-165. doi: 10.1111/imm. 12195

Hirakawa, S., Lange, E. M., Colicigno, C. J., Freedman, B. I., Rich, S. S., and Bowden, D. W. (2003). Evaluation of genetic variation and association in the matrix metalloproteinase 9 (MMP9) gene in ESRD patients. Am. J. Kidney Dis. 42, 133-142. doi: 10.1016/s0272-6386(03)00 $416-5$

Holoch, D., and Moazed, D. (2015). RNA-mediated epigenetic regulation of gene expression. Nat. Rev. Genet. 16, 71-84. doi: 10.1038/nrg3863

Janssen, B., Hohenadel, D., Brinkkoetter, P., Peters, V., Rind, N., Fischer, C., et al. (2005). Carnosine as a protective factor in diabetic nephropathy: association with a leucine repeat of the carnosinase gene CNDP1. Diabetes 54, 2320-2327. doi: 10.2337/diabetes.54.8. 2320
Jones, P. A. (2012). Functions of DNA methylation: islands, start sites, gene bodies and beyond. Nat. Rev. Genet. 13, 484-492. doi: 10.1038/nrg3230

Kaidonis, G., Gillies, M. C., Abhary, S., Liu, E., Essex, R. W., Chang, J. H., et al. (2016). A single-nucleotide polymorphism in the MicroRNA-146a gene is associated with diabetic nephropathy and sight-threatening diabetic retinopathy in Caucasian patients. Acta Diabetol. 53, 643-650. doi: 10.1007/ s00592-016-0850-4

Kang, W. L., and Xu, G. S. (2016). Atrasentan increased the expression of klotho by mediating miR-199b-5p and prevented renal tubular injury in diabetic nephropathy. Sci. Rep. 6:19979. doi: 10.1038/srep19979

Kato, M. (2018). Noncoding RNAs as therapeutic targets in early stage diabetic kidney disease. Kidney Res. Clin. Pract. 37, 197-209. doi: 10.23876/j.krcp.2018. 37.3.197

Kato, M., and Natarajan, R. (2014). Diabetic nephropathy-emerging epigenetic mechanisms. Nat. Rev. Nephrol. 10, 517-530. doi: 10.1038/nrneph.2014.116

Keating, S. T., van Diepen, J. A., Riksen, N. P., and El-Osta, A. (2018). Epigenetics in diabetic nephropathy, immunity and metabolism. Diabetologia 61, 6-20. doi: 10.1007/s00125-017-4490-1

Korabecna, M., Pazourkova, E., Horinek, A., Mokrejsova, M., and Tesar, V. (2013). Methylation status of immune response genes promoters in cell-free DNA differs in hemodialyzed patients with diabetic nephropathy according to the intensity of anemia therapy. Blood Purif. 36, 280-286. doi: 10.1159/000356094

Kurashige, M., Imamura, M., Araki, S., Suzuki, D., Babazono, T., Uzu, T., et al. (2013). The influence of a single nucleotide polymorphism within CNDP1 on susceptibility to diabetic nephropathy in Japanese women with type 2 diabetes. PLoS One 8:e54064. doi: 10.1371/journal.pone.0054064

Lappalainen, T., and Greally, J. M. (2017). Associating cellular epigenetic models with human phenotypes. Nat. Rev. Genet. 18, 441-451. doi: $10.1038 /$ nrg. 2017.32

Leak, T. S., Perlegas, P. S., Smith, S. G., Keene, K. L., Hicks, P. J., Langefeld, C. D., et al. (2009). Variants in intron 13 of the ELMO1 gene are associated with diabetic nephropathy in African Americans. Ann. Hum. Genet. 73, 152-159. doi: 10.1111/j.1469-1809.2008.00498.x

Lee, J. H., Choi, H. J., Lee, B. H., Kang, H. K., Chin, H. J., Yoon, H. J., et al. (2008). Prevalence of hypouricaemia and SLC22A12 mutations in healthy Korean subjects. Nephrology 13, 661-666. doi: 10.1111/j.1440-1797.2008.01029.x

Li, S. Y., Huang, P. H., Yang, A. H., Tarng, D. C., Yang, W. C., Lin, C. C., et al. (2014). Matrix metalloproteinase-9 deficiency attenuates diabetic nephropathy by modulation of podocyte functions and dedifferentiation. Kidney Int. 86, 358-369. doi: 10.1038/ki.2014.67

Lieb, W., Chen, M. H., Teumer, A., de Boer, R. A., Lin, H., and Fox, E. R. (2015). EchoGen consortium. Genome-wide meta-analyses of plasma renin activity and concentration reveal association with the kininogen 1 and prekallikrein genes. Circ. Cardiovasc. Genet. 8, 131-140. doi: 10.1093/hmg/ ddr092

Lim, S. C., Dorajoo, R., Zhang, X., Wang, L., Ang, S. F., Tan, C. S. H., et al. (2017). Genetic variants in the receptor for advanced glycation end products (RAGE) gene were associated with circulating soluble RAGE level but not with renal function among Asians with type 2 diabetes: a genome-wide association study. Nephrol. Dial. Transplant. 32, 1697-1704. doi: 10.1093/ndt/gfw263

Maeda, S., Imamura, M., Kurashige, M., Araki, S., Suzuki, D., Babazono, T., et al. (2013). Replication study for the association of 3 SNP loci identified in a genome-wide association study for diabetic nephropathy in European type 1 diabetes with diabetic nephropathy in Japanese patients with type 2 diabetes. Clin. Exp. Nephrol. 17, 866-871. doi: 10.1007/s10157-013-0797-5

Martini, S., Nair, V., Patel, S. R., Eichinger, F., Nelson, R. G., Weil, E. J., et al. (2013). From single nucleotide polymorphism to transcriptional mechanism: a model for FRMD3 in diabetic nephropathy. Diabetes 62, 2605-2612. doi: $10.2337 / \mathrm{db} 12-1416$

Marumo, T., Yagi, S., Kawarazaki, W., Nishimoto, M., Ayuzawa, N., Watanabe, A., et al. (2015). Diabetes induces aberrant DNA methylation in the proximal tubules of the kidney. J. Am. Soc. Nephrol. 26, 2388-2397. doi: 10.1681/ASN. 2014070665

McDonough, C. W., Hicks, P. J., Lu, L., Langefeld, C. D., Freedman, B. I., and Bowden, D. W. (2009). The influence of carnosinase gene polymorphisms on diabetic nephropathy risk in African-Americans. Hum. Genet. 126, 265-275. doi: 10.1007/s00439-009-0667-0 
McDonough, C. W., Palmer, N. D., Hicks, P. J., Roh, B. H., An, S. S., Cooke, J. N., et al. (2011). A genome-wide association study for diabetic nephropathy genes in African Americans. Kidney Int. 79, 563-572. doi: 10.1038/ki.2010.467

McKnight, A. J., Currie, D., Patterson, C. C., Maxwell, A. P., Fogarty, D. G., and Warren, 3/UK GoKinD Study Group. (2009). Targeted genome-wide investigation identifies novel SNPs associated with diabetic nephropathy. Hugo J. 3, 77-82. doi: 10.1007/s11568-010-9133-2

Mehrabzadeh, M., Pasalar, P., Karimi, M., Abdollahi, M., Daneshpour, M., Asadolahpour, E., et al. (2016). Association between ELMO1 gene polymorphisms and diabetic nephropathy in an Iranian population. J. Diabetes Metab. Disord. 15:43.

Mi, X., Tang, W., Chen, X., Liu, F., and Tang, X. (2016). Mitofusin 2 attenuates the histone acetylation at collagen IV promoter in diabetic nephropathy. J. Mol. Endocrinol. 57, 233-249. doi: 10.1530/JME-16-0031

Mone, F., Quinlan-Jones, E., and Kilby, M. D. (2018). Clinical utility of exome sequencing in the prenatal diagnosis of congenital anomalies: a review. Eur. J. Obstet. Gynecol. Reprod. Biol. 231, 19-24. doi: 10.1016/j.ejogrb.2018.10.016

Mooyaart, A. L., Zutinic, A., Bakker, S. J., Grootendorst, D. C., Kleefstra, N., van Valkengoed, I. G., et al. (2010). Association between CNDP1 genotype and diabetic nephropathy is sex specific. Diabetes 59, 1555-1559. doi: 10.2337/db091377

Murea, M., Ma, L., and Freedman, B. I. (2012). Genetic and environmental factors associated with type 2 diabetes and diabetic vascular complications. Rev. Diabet. Stud. 9, 6-22. doi: 10.1900/RDS.2012.9.6

Nair, S., Phillips, A. O., Norton, N., Spurlock, G., Williams, H. J., Craig, K. J., et al. (2008). Further evidence for the association of MMP9 with nephropathy in type 2 diabetes and application of DNA pooling technology to candidate gene screening. J. Nephrol. 21, 400-405.

Ni, X., Ji, C., Cao, G., Cheng, H., Guo, L., Gu, S., et al. (2003). Molecular cloning and characterization of the protein 4.10 gene, a novel member of the protein 4.1 family with focal expression in ovary. J. Hum. Genet. 48, 101-106. doi: $10.1007 / \mathrm{s} 100380300015$

Nicolas, A., Fatima, S., Lamri, A., Bellili-Muñoz, N., Halimi, J. M., Saulnier, P. J., et al. (2015). ABCG8 polymorphisms and renal disease in type 2 diabetic patients. Metabolism 64, 713-719. doi: 10.1016/j.metabol.2015.03.005

Nie, M., Bal, M. S., Liu, J., Yang, Z., Rivera, C., Wu, X. R., et al. (2018). Uromodulin regulates renal magnesium homeostasis through the ion channel transient receptor potential melastatin 6 (TRPM6). J. Biol. Chem. 293, 16488-16502. doi: 10.1074/jbc.RA118.003950

Nishiyama, K., Tanaka, Y., Nakajima, K., Mokubo, A., Atsumi, Y., Matsuoka, K., et al. (2005). Polymorphism of the solute carrier family 12 (sodium/chloride transporters) member 3, SLC12A3, gene at exon 23 (+78G/A: Arg913Gln) is associated with elevation of urinary albumin excretion in Japanese patients with type 2 diabetes: a 10-year longitudinal study. Diabetologia 48, 1335-1338. doi: 10.1007/s00125-005-1785-4

Palmer, N. D., and Freedman, B. I. (2013). Diabetic nephropathy: FRMD3 in diabetic nephropathy-guilt by association. Nat. Rev. Nephrol. 9, 313-314. doi: 10.1038/nrneph.2013.81

Palmer, N. D., Ng, M. C., Hicks, P. J., Mudgal, P., Langefeld, C. D., Freedman, B. I., et al. (2014). Evaluation of candidate nephropathy susceptibility genes in a genome-wide association study of African American diabetic kidney disease. PLoS One 9:e88273. doi: 10.1371/journal.pone.0088273

Papadopoulou-Marketou, N., Chrousos, G. P., and Kanaka-Gantenbein, C. (2017). Diabetic nephropathy in type 1 diabetes: a review of early natural history, pathogenesis, and diagnosis. Diabetes Metab. Res. Rev. 33:e2841. doi: 10.1002/ dmrr.2841

Patel, M., Margaron, Y., Fradet, N., Yang, Q., Wilkes, B., Bouvier, M., et al. (2010). An evolutionarily conserved autoinhibitory molecular switch in ELMO proteins regulates Rac signaling. Curr. Biol. 20, 2021-2027. doi: 10.1016/j.cub. 2010.10.028

Pendergrass, S. A., and Ritchie, M. D. (2015). Phenome-wide association studies: leveraging comprehensive phenotypic and genotypic data for discovery. Curr. Genet. Med. Rep. 3, 92-100. doi: 10.1007/s40142-0150067-9

Peng, R., Liu, H., Peng, H., Zhou, J., Zha, H., Chen, X., et al. (2015). Promoter hypermethylation of let-7a-3 is relevant to its down-expression in diabetic nephropathy by targeting UHRF1. Gene 570, 57-63. doi: 10.1016/j.gene.2015. 05.073
Peters, V., Kebbewar, M., Janssen, B., Hoffmann, G. F., Möller, K., and Wygoda, S. (2016). CNDP1 genotype and renal survival in pediatric nephropathies. J. Pediatr. Endocrinol. Metab. 29, 827-833. doi: 10.1515/jpem-2015-0262

Pezzolesi, M. G., Katavetin, P., Kure, M., Poznik, G. D., Skupien, J., Mychaleckyj, J. C., et al. (2009a). Confirmation of genetic associations at ELMO1 in the GoKinD collection supports its role as a susceptibility gene in diabetic nephropathy. Diabetes 58, 2698-2702. doi: 10.2337/db09-0641

Pezzolesi, M. G., Poznik, G. D., Mychaleckyj, J. C., Paterson, A. D., Barati, M. T., and Klein, J. B. (2009b). Genome-wide association scan for diabetic nephropathy susceptibility genes in type 1 diabetes. Diabetes 58, 1403-1410.

Prudente, S., Di Paola, R., Copetti, M., Lucchesi, D., Lamacchia, O., and Pezzilli, S. (2017). The rs12917707 polymorphism at the UMOD locus and glomerular filtration rate in individuals with type 2 diabetes: evidence of heterogeneity across two different European populations. Nephrol. Dial. Transplant. 32, 1718-1722. doi: 10.1093/ndt/gfw262

Rakyan, V. K., Down, T. A., Balding, D. J., and Beck, S. (2011). Epigenome-wide association studies for common human diseases. Nat. Rev. Genet. 12, 529-541. doi: 10.1038/nrg3000

Reddy, M. A., Sumanth, P., Lanting, L., Yuan, H., Wang, M., Mar, D., et al. (2014). Losartan reverses permissive epigenetic changes in renal glomeruli of diabetic db/db mice. Kidney Int. 85, 362-373. doi: 10.1038/ki.2013.387

Reidy, K., Kang, H. M., Hostetter, T., and Susztak, K. (2014). Molecular mechanisms of diabetic kidney disease. J. Clin. Invest. 124, 2333-2340. doi: 10.1172/JCI72271

Roden, D. M. (2017). Phenome-wide association studies: a new method for functional genomics in humans. J. Physiol. 595, 4109-4115. doi: 10.1113/ JP273122

Sandholm, N., Forsblom, C., Mäkinen, V. P., McKnight, A. J., Osterholm, A. M., and He, B. (2014). Genome-wide association study of urinary albumin excretion rate in patients with type 1 diabetes. Diabetologia 57, 1143-1153. doi: 10.1007/ s00125-014-3202-3

Sandholm, N., Haukka, J. K., Toppila, I., Valo, E., Harjutsalo, V., Forsblom, C., et al. (2018). Confirmation of GLRA3 as a susceptibility locus for albuminuria in Finnish patients with type 1 diabetes. Sci. Rep. 8:12408. doi: 10.1038/s41598018-29211-1

Sandholm, N., McKnight, A. J., Salem, R. M., Brennan, E. P., Forsblom, C., and Harjutsalo, V. (2013). FinnDiane Study Group and the GENIE Consortium. Chromosome 2q31.1 associates with ESRD in women with type 1 diabetes. J. Am. Soc. Nephrol. 24, 1537-1543. doi: 10.1681/ASN.2012111122

Sandholm, N., Salem, R. M., McKnight, A. J., Brennan, E. P., Forsblom, C., and Isakova, T. (2012). New susceptibility loci associated with kidney disease in type 1 diabetes. PLoS Genet. 8:e1002921. doi: 10.1371/journal.pgen.1002921

Sandholm, N., Van Zuydam, N., Ahlqvist, E., Juliusdottir, T., Deshmukh, H. A., and Rayner, N. W. (2017). The genetic landscape of renal complications in type 1 diabetes. J. Am. Soc. Nephrol. 28, 557-574. doi: 10.1681/ASN.2016020231

Sapienza, C., Lee, J., Powell, J., Erinle, O., Yafai, F., Reichert, J., et al. (2011). DNA methylation profiling identifies epigenetic differences between diabetes patients with ESRD and diabetes patients without nephropathy. Epigenetics 6, 20-28. doi: 10.4161/epi.6.1.13362

Sayyed, S. G., Gaikwad, A. B., Lichtnekert, J., Kulkarni, O., Eulberg, D., Klussmann, S., et al. (2010). Progressive glomerulosclerosis in type 2 diabetes is associated with renal histone $\mathrm{H} 3 \mathrm{~K} 9$ and $\mathrm{H} 3 \mathrm{~K} 23$ acetylation, H3K4 dimethylation and phosphorylation at serine 10. Nephrol. Dial. Transplant. 25, 1811-1817. doi: 10.1093/ndt/gfp730

Seman, N. A., Mohamud, W. N., Östenson, C. G., Brismar, K., and Gu, H. F. (2015). Increased DNA methylation of the SLC30A8 gene promoter is associated with type 2 diabetes in a Malay population. Clin. Epigenetics 7:30. doi: 10.1186/ s13148-015-0049-5

Shan, Q., Zheng, G., Zhu, A., Cao, L., Lu, J., Wu, D., et al. (2016). Epigenetic modification of miR-10a regulates renal damage by targeting CREB1 in type 2 diabetes mellitus. Toxicol. Appl. Pharmacol. 306, 134-143. doi: 10.1016/j.taap. 2016.06.010

Sharma, I., Dutta, R. K., Singh, N. K., and Kanwar, Y. S. (2017). High glucoseinduced hypomethylation promotes binding of Sp-1 to myo-inositol oxygenase: implication in the pathobiology of diabetic tubulopathy. Am. J. Pathol. 187, 724-739. doi: 10.1016/j.ajpath.2016.12.011

Sharma, K. R., Heckler, K., Stoll, S. J., Hillebrands, J. L., Kynast, K., Herpel, E., et al. (2016). ELMO1 protects renal structure and ultrafiltration in kidney 
development and under diabetic conditions. Sci. Rep. 6:37172. doi: 10.1038/ srep37172

Shiffman, D., Pare, G., Oberbauer, R., Louie, J. Z., Rowland, C. M., Devlin, J. J., et al. (2014). A gene variant in CERS2 is associated with rate of increase in albuminuria in patients with diabetes from ONTARGET and TRANSCEND. PLoS One 9:e106631. doi: 10.1371/journal.pone.0106631

Shimazaki, A., Kawamura, Y., Kanazawa, A., Sekine, A., Saito, S., Tsunoda, T., et al. (2005). Genetic variations in the gene encoding ELMO1 are associated with susceptibility to diabetic nephropathy. Diabetes 54, 1171-1178. doi: 10.2337/ diabetes.54.4.1171

Shimazaki, A., Tanaka, Y., Shinosaki, T., Ikeda, M., Watada, H., Hirose, T., et al. (2006). ELMO1 increases expression of extracellular matrix proteins and inhibits cell adhesion to ECMs. Kidney Int. 70, 1769-1776. doi: 10.1038/sj.ki. 5001939

Smyth, L. J., Maxwell, A. P., Benson, K. A., Kilner, J., McKay, G. J., and McKnight, A. J. (2018). Validation of differentially methylated microRNAs identified from an epigenome-wide association study; Sanger and next generation sequencing approaches. BMC Res. Notes 11:767. doi: 10.1186/s13104-018-3872-x

Sun, G., Reddy, M. A., Yuan, H., Lanting, L., Kato, M., and Natarajan, R. (2010). Epigenetic histone methylation modulates fibrotic gene expression. J. Am. Soc. Nephrol. 21, 2069-2080. doi: 10.1681/ASN.2010060633

Sun, X. Y., Qin, H. J., Zhang, Z., Xu, Y., Yang, X. C., Zhao, D. M., et al. (2016). Valproate attenuates diabetic nephropathy through inhibition of endoplasmic reticulum stress-induced apoptosis. Mol. Med. Rep. 13, 661-668. doi: 10.3892/ mmr.2015.4580.

Swan, E. J., Maxwell, A. P., and McKnight, A. J. (2015). Distinct methylation patterns in genes that affect mitochondrial function are associated with kidney disease in blood-derived DNA from individuals with Type 1 diabetes. Diabet. Med. 32, 1110-1115. doi: 10.1111/dme.12775

Tanaka, N., Babazono, T., Saito, S., Sekine, A., Tsunoda, T., Haneda, M., et al. (2003). Association of solute carrier family 12 (sodium/chloride) member 3 with diabetic nephropathy, identified by genome-wide analyses of single nucleotide polymorphisms. Diabetes 52, 2848-2853. doi: 10.2337/diabetes.52.11.2848

Teumer, A., Tin, A., Sorice, R., Gorski, M., Yeo, N. C., and Chu, A. Y. (2016). Genome-wide association studies identify genetic loci associated with albuminuria in diabetes. Diabetes 65, 803-817. doi: 10.2337/db15-1313

Thameem, F., Igo, R. P. Jr., Freedman, B. I., Langefeld, C., Hanson, R. L., and Schelling, J. R. (2013). Family investigation of nephropathy and diabetes research group. A genome-wide search for linkage of estimated glomerular filtration rate (eGFR) in the family investigation of nephropathy and diabetes (FIND). PLoS One 8:e81888. doi: 10.1371/journal.pone.0081888

Thomas, M. C. (2016). Epigenetic mechanisms in diabetic kidney disease. Curr. Diab. Rep. 16:31. doi: 10.1007/s11892-016-0723-9

Thomas, M. C., Brownlee, M., Susztak, K., Sharma, K., Jandeleit-Dahm, K. A., Zoungas, S., et al. (2015). Diabetic kidney disease. Nat. Rev. Dis. Primers 1:15018. doi: 10.1038/nrdp.2015.18

Thomas, M. C., Groop, P. H., and Tryggvason, K. (2012). Towards understanding the inherited susceptibility for nephropathy in diabetes. Curr. Opin. Nephrol. Hypertens. 21, 195-202. doi: 10.1097/MNH.0b013e328350313e

Tikoo, K., Meena, R. L., Kabra, D. G., and Gaikwad, A. B. (2008). Change in post-translational modifications of histone $\mathrm{H} 3$, heat-shock protein-27 and MAP kinase p38 expression by curcumin in streptozotocin-induced type I diabetic nephropathy. Br. J. Pharmacol. 153, 1225-1231. doi: 10.1038/sj.bjp.0707666

Treangen, T. J., and Salzberg, S. L. (2011). Repetitive DNA and next-generation sequencing: computational challenges and solutions. Nat. Rev. Genet. 13, 36-46. doi: $10.1038 / \mathrm{nrg} 3117$

van Dijk, E. L., Jaszczyszyn, Y., Naquin, D., and Thermes, C. (2018). The third revolution in sequencing technology. Trends Genet. 34, 666-681. doi: 10.1016/ j.tig.2018.05.008

van Zuydam, N. R., Ahlqvist, E., Sandholm, N., Deshmukh, H., Rayner, N. W., and Abdalla, M. S. (2018). A genome-wide association study of diabetic kidney disease in subjects with type 2 diabetes. Diabetes 67, 1414-1427. doi: 10.2337/ db17-0914

VanderJagt, T. A., Neugebauer, M. H., Morgan, M., Bowden, D. W., and Shah, V. O. (2015). Epigenetic profiles of pre-diabetes transitioning to type 2 diabetes and nephropathy. World J. Diabetes 6, 1113-1121. doi: 10.4239/wjd.v6. i9.1113

Villeneuve, L. M., and Natarajan, R. (2010). The role of epigenetics in the pathology of diabetic complications. Am. J. Physiol. Renal Physiol. 299, F14-F25. doi: 10.1152/ajprenal.00200.2010

Wang, T., Zhang, Y., Wang, N., Liu, Q., Wang, Z., Liu, B., et al. (2018). Synergistical action of the $\beta 2$ adrenoceptor and fatty acid binding protein 2 polymorphisms on the loss of glomerular filtration rate in Chinese patients with type 2 diabetic nephropathy. Int. Urol. Nephrol. 50, 715-723. doi: 10.1007/s11255-018-1812-2

Wanic, K., Placha, G., Dunn, J., Smiles, A., Warram, J. H., and Krolewski, A. S. (2008). Exclusion of polymorphisms in carnosinase genes (CNDP1 and CNDP2) as a cause of diabetic nephropathy in type 1 diabetes: results of large case-control and follow-up studies. Diabetes 57, 2547-2551. doi: 10.2337/db071303

Watanabe, A., Marumo, T., Kawarazaki, W., Nishimoto, M., Ayuzawa, N., Ueda, K., et al. (2018). Aberrant DNA methylation of pregnane X receptor underlies metabolic gene alterations in the diabetic kidney. Am. J. Physiol. Renal Physiol. 314, F551-F560. doi: 10.1152/ajprenal.00390. 2017

Wu, H. Y., Wang, Y., Chen, M., Zhang, X., Wang, D., Pan, Y., et al. (2013). Association of ELMO1 gene polymorphisms with diabetic nephropathy in Chinese population. J. Endocrinol. Invest. 36, 298-302. doi: 10.3275/8525

Yang, L., Zhang, Q., Wu, Q., Wei, Y., Yu, J., Mu, J., et al. (2018). Effect of TET2 on the pathogenesis of diabetic nephropathy through activation of transforming growth factor $\beta 1$ expression via DNA demethylation. Life Sci. 207, 127-137. doi: 10.1016/j.lfs.2018.04.044

Yang, X. H., Cao, R. F., Yu, Y., Sui, M., Zhang, T., Xu, J. Y., et al. (2016). A study on the correlation between MTHFR promoter methylation and diabetic nephropathy. Am. J. Transl. Res. 8, 4960-4967.

Yuan, H., Reddy, M. A., Deshpande, S., Jia, Y., Park, J. T., Lanting, L. L., et al. (2016). Epigenetic histone modifications involved in profibrotic gene regulation by 12/15-lipoxygenase and its oxidized lipid products in diabetic nephropathy. Antioxid. Redox Signal. 24, 361-375. doi: 10.1089/ars.2015. 6372

Zhang, H., Cai, X., Yi, B., Huang, J., Wang, J., and Sun, J. (2014). Correlation of CTGF gene promoter methylation with CTGF expression in type 2 diabetes mellitus with or without nephropathy. Mol. Med. Rep. 9, 2138-2144. doi: 10. 3892/mmr.2014.2067

Zhang, L., Zhang, Q., Liu, S., Chen, Y., Li, R., Lin, T., et al. (2017). DNA methyltransferase 1 may be a therapy target for attenuating diabetic nephropathy and podocyte injury. Kidney Int. 92, 140-153. doi: 10.1016/j.kint. 2017.01.010

Zhang, R., Zhuang, L., Li, M., Zhang, J., Zhao, W., Ge, X., et al. (2018). Arg913Gln of SLC12A3 gene promotes development and progression of end-stage renal disease in Chinese type 2 diabetes mellitus. Mol. Cell. Biochem. 437, 203-210. doi: 10.1007/s11010-017-3120-z

Zhang, Z., Wu, X., Cai, T., Gao, W., Zhou, X., Zhao, J., et al. (2015). Matrix metalloproteinase 9 gene promoter (rs3918242) mutation reduces the risk of diabetic microvascular complications. Int. J. Environ. Res. Public Health 12, 8023-8033. doi: 10.3390/ijerph120708023

Zhou, T. B., Drummen, G. P., Jiang, Z. P., and Li, H. Y. (2015). Methylenetetrahydrofolate reductase (MTHFR) C677T gene polymorphism and diabetic nephropathy susceptibility in patients with type 2 diabetes mellitus. Ren. Fail. 37, 1247-1259. doi: 10.3109/0886022X.2015.1064743

Conflict of Interest Statement: The author declares that the research was conducted in the absence of any commercial or financial relationships that could be construed as a potential conflict of interest.

Copyright (C) $2019 \mathrm{Gu}$. This is an open-access article distributed under the terms of the Creative Commons Attribution License (CC BY). The use, distribution or reproduction in other forums is permitted, provided the original author(s) and the copyright owner(s) are credited and that the original publication in this journal is cited, in accordance with accepted academic practice. No use, distribution or reproduction is permitted which does not comply with these terms. 